\title{
Pre-B cell receptor acts as a selectivity switch for Galectin-1 at the pre-B cell surface
}

Pauline Touarin ${ }^{1}$, Bastien Serrano ${ }^{1}$, Audrey Courbois ${ }^{1}$, Olivier Bornet ${ }^{2}$, Qian Chen $^{3}$, Lincoln

G. Scott ${ }^{3}$, Stéphane J.C. Mancini ${ }^{4}$, James R. Williamson ${ }^{5}$, Corinne Sebban-Kreuzer ${ }^{1}$ and Latifa Elantak ${ }^{1 *}$

${ }^{1}$ Laboratoire d'Ingénierie des Systèmes Macromoléculaires, UMR7255, Institut de Microbiologie de la Méditerranée, Institut de Microbiologie, Bioénergies et Biotechnologies, CNRS, Aix-Marseille Université, Marseille, France

${ }^{2}$ NMR platform, Institut de Microbiologie de la Méditerranée, Institut de Microbiologie, Bioénergies et Biotechnologies, CNRS, Aix-Marseille Université, Marseille, France

${ }^{3}$ Cassia, LLC, 3030 Bunker Hill Street, Ste. 214, San Diego, California 92109, USA

${ }^{4}$ Univ Rennes, INSERM, EFS, UMR S1236, Rennes, France

${ }^{5}$ Department of Integrative Structural and Computational biology, The Scripps Research Institute, La Jolla, CA 92037, USA

*email : elantak@imm.cnrs.fr 


\begin{abstract}
Galectins are glycan binding proteins translating the sugar-encoded information of cellular glycoconjugates into many physiological activities including immunity, cell migration, and signaling. During early B lymphocytes (BL) development at the pre-B cell stage, BL express the pre-B cell receptor (pre-BCR) and are supported by mesenchymal stromal cells secreting Galectin-1 (Gal-1). Gal-1 interacts with glycosylated receptors from stromal and pre-B cell surfaces but also with the pre-BCR through a direct carbohydrate-independent contact. How this interaction might interplay with the glycan-decoding function of Gal-1 is unknown. Here, we investigated Gal-1 binding to cell surface ligands using NMR spectroscopy on native membranes. We showed that pre-BCR regulates Gal-1 binding to specifically target $\alpha 2,3-$ sialylated receptors on pre-B cells. Upon pre-BCR interaction, dynamic changes resulted in additional contacts with $\alpha 2,3$-sialylated glycans converting Gal-1 from an exo- to an endotype lectin. Remarkably, this selectivity switch is able to promote pre-B cell survival. Altogether, we shed light on a new mechanism allowing fine-tuning of Galectin specificity at the cell surfaces.
\end{abstract}




\section{Introduction}

Glycans are essential for life and play many different fundamental roles in nearly all biological processes ${ }^{1}$. Their tremendous diversity is key to store chemical information at the cell surfaces, called «glycocode», which is translated into cellular responses by binding to specific proteins mainly known as lectins ${ }^{2,3}$. Among lectins, Galectins are a highly conserved family of fifteen known proteins (Gal-1 to Gal-15), defined by their ability to bind $\beta$ galactosides through a conserved carbohydrate recognition domain (CRD) which includes the carbohydrate binding site $(\mathrm{CBS})^{4}$. These lectins, found in many cell types ${ }^{5}$, are well-known regulators of cell responses and mediate a wide variety of functions such as cell binding, migration, differentiation, cellular trafficking, and cell signaling ${ }^{4}$. Galectins are also involved in several pathological processes such as inflammatory diseases, oncogenesis, cardiovascular disorders, and host-pathogen interactions ${ }^{6-10}$, making Galectins attractive therapeutic targets ${ }^{11-13}$. All these functions, at the surface of many different cell types, in all kind of environments, are achieved through their capability to oligomerize which leads to crosslinking of specific cell-surface glycoproteins or glycolipids into lattices ${ }^{14}$. Given the abundance of $\beta$-galactoside-derived glycoconjugates on cell surfaces, how these lectins select a subset of ligands among many available candidates to mediate a specific cellular function remains elusive.

The concept of Galectins as functioning in the extracellular compartment only through carbohydrate interactions has been recently challenged by the identification of nonglycosylated binding partners ${ }^{15-18}$. Whether these interactions participate to cell glycome decoding by Galectins is unknown. The first example of a carbohydrate-independent interaction in the extracellular compartment concerns the prototype Gal-1 homodimer and the pre-B cell receptor (pre-BCR) ${ }^{19}$. Gal-1 is an exo-type lectin i.e. it interacts specifically with terminal units of polysaccharides ${ }^{20,21}$. During B cell differentiation in the bone marrow, pre- 
BCRs are expressed at the surface of pre-B cells, which are present in a specialized cellular niche consisting of stromal cells secreting Gal-1. At this developmental stage, Gal-1 establishes interactions with glycoconjugates and the pre-BCRs at the contact zone between pre-B and stromal cells ${ }^{19,22}$. This Gal-1-dependent lattice drives pre-BCRs clustering, activation, and subsequent downstream signaling which has been implicated in cell survival, proliferation, and differentiation ${ }^{23}$. However, the molecular mechanism underlying Gal-1 functions at the pre-B cell surface remains unknown. Our previous study revealed that Gal-1 interacts with a non-glycosylated region of the pre-BCR, the $\lambda 5$ unique region ( $\lambda 5$-UR), that docks onto a Gal-1 hydrophobic surface behind the $\mathrm{CBS}^{24}$. While binding at distance from the CBS, $\lambda 5$-UR induces carbohydrate affinity changes as tested on glycan arrays ${ }^{15}$. These data suggested that $\lambda 5$-UR binding to Gal-1 modulates Gal-1 binding activity for structurally related carbohydrates, decreasing affinity for branched and linear poly-N-acetylactosamine (poly-LacNAc) and increasing affinity for sulfated or $\alpha 2,3$ sialylated poly-LacNAc. Whether these affinity changes represent a mechanism to regulate Gal-1 interactions and function at the pre-B cell surface is still to be demonstrated on physiological cell surface ligands embedded in the plasma membrane. To date there are no published data analyzing at the structural level Galectin binding to native cell surface ligand.

Here, we addressed the challenge of studying Gal-1 binding to pre-B and stromal cell surfaces using solution-state "on-cell" NMR spectroscopy and investigated the effect of $\lambda 5$ UR interaction on Gal-1 binding to its physiological ligands. We show that $\lambda 5$-UR allows Gal-1 to select specific glycosylated receptors at the pre-B cell surface. We identified $\alpha 2,3-$ sialylated glycans as key targeted epitopes and demonstrated in vivo that this regulation can rescue pre-B cells from cell death. Defining the structural basis of this regulation highlighted a switch converting Gal-1 from an exo- to an endo-type lectin upon $\lambda 5$-UR interaction. Altogether, our study shows that Galectin/non-glycosylated protein interactions can act as 
regulators of Galectin functions and may be the missing piece of the puzzle to understand how Galectins acquire their target specificity at the cell surfaces.

\section{Results}

\section{NMR reveals the structural basis of Gal-1 binding to cell surface ligands}

To investigate Gal-1 binding to glycoconjugates in their native membrane environment, we utilized stromal and pre-B cell lines (OP9 and Nalm6, respectively) to extract glycoconjugates-enriched membrane vesicles amenable for NMR studies. These cell lines were previously used to model the pre-B/stromal cell synapse and pre-BCR relocalization ${ }^{24}$. For reference, we characterized these membrane vesicle preparations by negative stain electron microscopy and observed on average $50 \mathrm{~nm}$ and $25 \mathrm{~nm}$ diameter vesicles extracted from stromal and pre-B cell lines, respectively (Supplementary Fig. 1a and 1b). NMR experiments carried out consisted in recording ${ }^{1} \mathrm{H},{ }^{15} \mathrm{~N}$ HSQC spectra on ${ }^{15} \mathrm{~N}$-labeled Gal-1 alone and incubated with membrane vesicles (Fig. 1a). Upon vesicle addition, chemical shift deviations (CSDs) and line broadening were observed, indicative of complex formation with vesicle surface ligands (Fig. 1b and Supplementary Fig. 1c and 1d). To provide evidence that glycans are mediating Gal-1 binding to cell vesicles, we released complex N- and O-glycans from the cell surface by enzymatic cleavage using PNGase F and O-glycosidase. After treatment, no variation nor intensity decrease were observed on Gal-1 spectra confirming that Gal-1 interaction to cell vesicles is glycan-dependent (Fig. 1b and Supplementary Fig. 1e). These results demonstrate not only the presence of functional glycosylated ligands in the isolated membrane vesicles but also the possibility to monitor Gal-1 interactions at atomic resolution in their physiological context.

Remarkably, Gal-1 resonances presenting CSDs are localized in the CBS (Fig. 1c and 1d). Previously, the Gal-1 CBS has been defined as containing five subsites, A to E, where subsite 
$\mathrm{C}$ is accommodating the essential $\beta$-galactose unit, the other subsites interacting more specifically with the other units of the glycan ${ }^{25}$. When incubated with cell vesicles, CBS subsites $\mathrm{C}$ and $\mathrm{D}$ were mainly perturbed, thus confirming Gal-1 binding to cell surface $\beta$ galactosides (Fig. 1c, 1d and Supplementary Fig. 2b and 2c). However, significant differences were observed at the residue level depending on the cell vesicles added. Remarkably, additional perturbations in CBS subsites $\mathrm{A}$ and $\mathrm{E}$ were observed in the presence of stromal cell vesicles, indicating binding to $\beta$-galactoside ligands with extensions pointing towards these subsites (Fig. 1d and Supplementary Fig. 2c). In addition to CBS perturbations, residues on the Gal-1 backside surface showed strong CSDs (Fig. 1c and 1d). These variations outside the CBS could represent an additional interaction site for extended complex cellular glycans. Several of these resonances experienced CSDs with both stromal and pre-B vesicles while some others are perturbed only with pre-B (A75, F77) or stromal (K28, C88, D102) vesicles, illustrating differences at the residue level depending on which cell vesicles were added. Finally, residues at the dimer interface showed CSDs (Fig. 1c and 1d) but also the strongest peak intensity decrease (Supplementary Fig. $2 \mathrm{~b}$ and 2c), indicating that cell surface ligand binding to the CBS induces a long-range effect resulting in the stabilization of the dimer state. Altogether, these data show that Gal-1 binding to cell surface glycosylated ligands impact not only the CBS but also other regions of the CRD (backside and dimer interface). Ultimately, while binding to glycoconjugates containing $\beta$-galactosides, significant differences are also observed at the residue level demonstrating that pre-B and stromal cells contain different sets of Gal-1 ligands. These results are in agreement with lectin microarrays data on pre-B and stromal cells showing cell specific glycomic signatures ${ }^{15}$.

\section{$\lambda 5-\mathrm{UR}$ regulates Gal-1 binding to pre-B cell ligands to target specific glycan epitopes}

Within the pre-B cell niche, Gal-1 secreted by stromal cells contacts pre-B cells through binding to glycosylated receptors and to $\lambda 5$-UR from the pre-BCR ${ }^{19,22}$. To determine whether 
$\lambda 5$-UR can change Gal-1 binding properties to pre-B cell glycosylated ligands, we examined the effect of $\lambda 5$-UR on the resulting ${ }^{1} \mathrm{H},{ }^{15} \mathrm{~N}$-HSQC spectra of Gal-1 in the presence of pre-B cell vesicles.

When added to Gal-1 bound to pre-B cell vesicles, $\lambda 5$-UR induced CSDs in the $\lambda 5$-UR binding site and within the CBS (Fig. 2a and 2b, Supplementary Fig. 3a). Remarkably, several of these resonances were already affected by pre-B vesicles interaction but, upon $\lambda 5$-UR binding, they shifted in the opposite direction towards their initial Gal-1 free resonance position (Fig. 2b). Calculated CSDs for these resonances decreased until complete cancelation

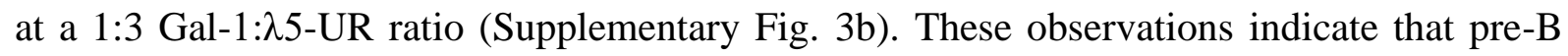
cell ligands of Gal-1 are counter-selected in the presence of $\lambda 5$-UR. Then, upon increasing $\lambda 5$ UR addition, other CBS resonances located in CBS subsites $\mathrm{B}$ and $\mathrm{C}$, and in loops surrounding the CBS started to shift are (Fig. 2b, 2c and Supplementary Fig. 3b). Consequently, the final binding pattern of Gal-1 to pre-B cell vesicles is different in the presence of $\lambda 5$-UR indicating binding to new ligands (Fig. 1c vs. Fig. 2b). A control peptide, $\lambda 5$-UR mutated on two essential residues for complex formation with Gal-1 ( $\lambda 5$-UR-L26A$\mathrm{W} 30 \mathrm{~A})^{24}$, has been used to verify that the effect observed is specific to $\lambda 5$-UR binding to Gal1 and not due to non-specific binding of $\lambda 5$-UR to cell vesicle ligands. No CSDs were observed with the mutated peptide (Fig. 2a and Supplementary Fig. 3c). Collectively, these experiments demonstrate glycan binding changes for Gal-1 at the pre-B cell surface upon $\lambda 5$ UR interaction, decreasing affinity for some glycan epitopes and enhancing interaction with others.

Next, we set out to investigate what could be the $\lambda 5$-UR effect on Gal-1 binding within the pre-B cell niche meaning when pre-B and stromal cell ligands are present. To mimic the preB cell niche, we mixed stromal and pre-B cell vesicles (Fig. 2d and Supplementary Fig. 4). Chemical shift variations observed in CBS subsites B and C were similar to the ones found 
when Gal-1 was titrated with $\lambda 5$-UR in the presence of pre-B cell vesicles. These results indicate that, when pre-B and stromal cell ligands are present, $\lambda 5$-UR regulates Gal-1 binding to target specific glycoconjugates on pre-B cells.

\section{Dynamic allosteric coupling mediate $\lambda 5$-UR-induced Gal-1 regulation}

How $\lambda 5$-UR binding on Gal-1 backside is transmitted to the CBS to target specific glycoconjugates is a fundamental question. A hypothesis would be an allosteric coupling throughout Gal-1 from the $\lambda 5$-UR binding site to the CBS. Allostery involves coupling of ligand binding at one site with a conformational or dynamic change at a distant site, thereby affecting binding at that site. No structural changes within the Gal-1 CBS had been observed upon binding of $\lambda 5-\mathrm{UR}^{24}$, hence we investigated the role of dynamics in the regulation of Gal1 interactions mediated by $\lambda 5$-UR. The backbone dynamics of Gal-1 were analyzed using nuclear spin relaxation parameters for Gal-1 free and bound to $\lambda 5$-UR (Supplementary Fig. 5). The role of fast protein motions was determined by measuring changes in the order parameter $\mathrm{S}^{2} . \mathrm{S}^{2}$ is a measure of the amplitude of internal motions on the picosecond-to-nanosecond timescale and can vary from $S^{2}=1$, for a bond vector with no internal motion, to $S^{2}=0$, for a bond vector that is rapidly sampling multiple orientations ${ }^{26} . \lambda 5-\mathrm{UR}$ binding to Gal-1 caused a large number of residues to decrease their motions as evidenced by the corresponding increase in their $S^{2}$ values (Fig. 3a). More specifically, $\lambda 5$-UR binding to Gal-1 resulted in line broadening and increased rigidity (increased $S^{2}$ ) for residues from the $\lambda 5$-UR binding site but also for residues from the upper loop of the CBS subsite C and within subsite D and B (Fig. 3b). By contrast, increased flexibility (decreased $S^{2}$ ) was observed for the lower loop of the CBS subsite C. It should be noted that chemical shift analysis showed that $\lambda 5$-UR binding to Gal-1 in the presence of pre-B cell vesicles (Fig. 2b) elicited changes in chemical shift for resonances precisely located within the same regions. These findings support the idea of an 
allostery-based regulation of Gal-1 binding activity triggered by $\lambda 5$-UR interaction in order to select specific glycan epitopes on pre-B cells.

\section{$\lambda 5$-UR regulates binding of Gal-1 by selecting $\alpha 2,3$-sialylated glycan motifs found on pre-B cell surface}

Our previous glycome exploration of pre-B and stromal cells highlighted a glycomic signature specific to pre-B cells corresponding to biantennary N-glycans, sulfated- and $\alpha 2,3$-sialylated $\beta$-galactoside glycans ${ }^{15}$. Importantly, the latter showed increased binding to Gal-1 on glycan arrays in the presence of $\lambda 5-\mathrm{UR}^{15}$. In addition, sialylated glycans have been shown to be involved in immunological processes ${ }^{27,28}$. We therefore hypothesized that $\alpha 2,3$ sialylated glycans could be one of the specific glycosidic epitopes targeted by Gal-1 at the pre-B cell surface. To test this hypothesis on live cells, pre-B cells were incubated with the MAL II lectin which specifically recognize $\alpha 2,3$-sialylated glycans and is thus expected to antagonize Gal-1 binding. Remarkably, when incubated with MAL II, cells showed a strong loss in viability (Fig. 4a) indicating that interaction of MAL II with the broad range of $\alpha 2,3$-sialylated receptors at the pre-B cell surface triggers a signaling pathway leading to cell death (Fig. 4b). Neither Gal-1 nor $\lambda 5$-UR reversed the induction of cell death by MAL II, thus illustrating their individual inability to perturb MAL II interactions with $\alpha 2,3$-sialylated receptors (Fig. 4a and 4c). However, when Gal-1 is combined to $\lambda 5$-UR, the MAL II-induced cell death was significantly inhibited (Fig. 4a). These observations demonstrate that $\lambda 5$-UR binding to Gal-1 provokes increased affinity for $\alpha 2,3$-sialylated receptors containing $\beta$-galactosides, perturbing MAL II network interactions and precluding cell death signaling (Fig. 4d). Of note, in the absence of MAL-II, neither Gal-1, $\lambda 5$-UR or a combination of both are able to induce strong pre-B cell death as seen with MAL II (Fig. 4a). Altogether, these results demonstrate that $\lambda 5$ UR mediates Gal-1 specific targeting of ligands containing $\alpha 2,3$-sialyl moieties at the pre-B 
cell surface and can promote pre-B cell survival. The structural basis of such ligand binding selection remains to be unraveled.

\section{$\lambda 5-U R$ induces increased Gal-1 contacts with $\alpha 2,3$ sialylated di-LacNAc, converting Gal-}

\section{1 from exo- to endo-type lectin}

To further investigate at atomic resolution the effect of $\lambda 5$-UR on the Gal-1/ $\alpha 2,3$ sialylated glycan interaction, we synthesized using a chemo-enzymatic based methodology the $\alpha 2,3$ sialyl di-LacNAc pentasaccharide called hereafter SdiLN (Supplementary Fig. 6a). Since galactose moieties are essential to Gal-1 binding, we also synthesized the pentasaccharide fully ${ }^{13} \mathrm{C}$-labeled on the galactose moieties (Supplementary Fig. 6). First, we tested its interaction with Gal-1 using saturation transfer difference (STD) NMR spectroscopy. This technique is based on selective irradiation of protein protons and subsequent detection of magnetization transfer to small ligands ${ }^{29,30}$. In the presence of Gal-1, magnetization transfer was observed indicating intermolecular contacts with the pentasaccharide (Fig. 5a). The STD signal mainly arises from interaction with the terminal galactose $\left(\mathrm{Gal}_{\mathrm{A}}\right)$ as expected for an exo-type lectin (Fig. 5a and Supplementary Fig. 7a). In addition, ${ }^{1} \mathrm{H},{ }^{13} \mathrm{C}-\mathrm{HSQC}$ spectra recorded before and after addition of Gal-1 to the ${ }^{13} \mathrm{C}$-labeled SdiLN showed severe peak loss for $\mathrm{Gal}_{\mathrm{A}}$ which is therefore the core binding unit to Gal-1 (Fig. 5b and 5c). These data are consistent with the Gal-1 classification as an exo-type lectin ${ }^{31,32}$. Remarkably, while only galactose moieties were ${ }^{13} \mathrm{C}$-labeled, peaks corresponding to resonances from the terminal $\mathrm{N}$ acetyl glucosamine (GlcNAc) and sialic acid (NeuAc) were visible on the HSQC spectrum in the presence of Gal-1 (Fig. 5b). This observation suggests that binding to the protein changes the dynamic of these groups resulting in a higher flexibility which, combined to the HSQC experiment sensitivity, make them visible on the spectrum despite the weak ${ }^{13} \mathrm{C}$ natural abundance. The reverse experiment, where Gal-1 is ${ }^{15} \mathrm{~N}$-labeled and the SdiLN is unlabeled has also been performed and showed CSDs and decreased peak intensities mainly for Gal-1 
resonances located in $\mathrm{CBS}$ subsite $\mathrm{C}$ where the core binding galactose $\mathrm{Gal}_{\mathrm{A}}$ of the $\mathrm{SdiLN}$ is likely interacting (Fig. 5d and Supplementary Fig. 8). Surprisingly, in the presence of $\lambda 5$-UR, STD signal contributions became equivalent for $\mathrm{Gal}_{\mathrm{A}}$ and $\mathrm{Gal}_{\mathrm{B}}$ demonstrating that Gal-1 interaction is not exclusive to the terminal galactose when bound to $\lambda 5-\mathrm{UR}$ (Fig. $5 \mathrm{e}$ and Supplementary Fig. 7b). As well, ${ }^{1} \mathrm{H},{ }^{13} \mathrm{C}-\mathrm{HSQC}$ spectrum of SdiLN showed loss of $\mathrm{Gal}_{\mathrm{A}}$ and $\mathrm{Gal}_{\mathrm{B}}$ resonances upon addition of $\lambda 5$-UR confirming interaction with both terminal and internal galactose (Fig. 5f and 5g). Moreover, NeuAc and GlcNAc resonances diseappeared indicating increased contacts with these glycan moieties. On the Gal-1 side, addition of $\lambda 5$ UR to the Gal-1/SdiLN complex not only intensified the initial perturbations but also propagated the effect towards CBS subsites A to E illustrating increased intermolecular contacts throughout the CBS with the pentasaccharide (Fig. 5h and Supplementary Fig. 8). $\lambda 5$-UR alone (without the SdiLN) is not able to prompt such Gal-1 signal intensity decrease which is consistent with the binding of a 24 amino acid peptide in fast exchange regime ${ }^{13}$. Thus, $\lambda 5$-UR interaction modifies Gal-1 binding to $\alpha 2,3$ sialylated glycan by allowing additional contacts with the pentasaccharide including with the internal galactose unit. While recent studies have elegantly rubber-stamped the selectivity of Gal-1 towards terminal galactose $^{21}$, here we establish that $\lambda 5$-UR binding to Gal-1 induces a selectivity switch converting Gal-1 from an exclusive exo-type lectin to an endo-type lectin interacting with both terminal and internal galactose units (Fig. 5i). This switch is therefore at the basis of Gal1 target specificity at the pre-B cell surface.

\section{Discussion}

Over the past decades, many cellular activities have been ascribed to Galectins ${ }^{4}$. Such a wide range of functions in so many cell types and environments have conducted many laboratories to develop methodologies to understand the varied and intricate roles played by these 
ubiquitous lectins. While many of these experiments developed provide evidence and enable visualization for Galectin-glycoprotein lattices on cell surfaces ${ }^{33,34}$, further studies were needed to understand the Galectins structural features regulating lattice assembly/disassembly at the cellular level. Here, we directly examined for the first time the structural properties of Gal-1 binding to native membranes by combining solution-state NMR spectroscopy to the preparation of pre-B and stromal membrane vesicles. Importantly, we could demonstrate that Gal-1 binding to its physiological cellular ligands involves long-range effects throughout the CRD beyond the canonical CBS limits. While multivalency of Gal-1 and its glycoconjugate ligands is essential for the formation of supramolecular lattices ${ }^{35}$, the additional interaction surface revealed for extended complex sugar (Fig. 1c and 1d) as well as the conformational exchange observed (Supplementary Fig. 2b and 2c) for residues at the dimer interface could be a key mechanism allowing increased overall stability and biological functionality of the assembled lattice on the cell surface.

Remarkably, our on-cell NMR approach allowed us to address how Gal-1 is able to decode the glycome of pre-B cells. Indeed, given the abundance of $\beta$-galactosides on the cell in the form of glycoproteins and surface glycolipids, one would expect that Galectin/glycoconjugates lattice translates into a large heterogeneous complex on the surface of cells. But conversely, this lectin is able to cross-link a single species of glycoproteins to form a uniform lattice $34,36,37$. Here, we demonstrate that Gal-1 is able to achieve target specificity at the pre-B cell surface through a direct interaction with a non-glycosylated protein domain of the pre-BCR, $\lambda 5$-UR. This interaction allows Gal-1 to interact with $\alpha 2,3$ sialylated glycoconjugates. Sialic acids are ubiquitously and abundantly found on the surface of all human cells as the terminating sugar in glycolipids (gangliosides) and glycoproteins (complex N-glycans and mucin type O-linked glycans). Moreover, sialic acids have been shown to play essential roles in immunological processes and in particular during $\mathrm{B}$ cell 
receptor (BCR) signaling ${ }^{28,35,38-40}$. In this context, the $\alpha 2,6$ sialylated $\mathrm{CD} 22$ receptor, which is a lectin recognizing $\alpha 2,6$ sialylated glycoreceptors, is recruited close to the BCR and inhibits its downstream signaling (Fig. 6a). The objective of this control being to prevent inadvertent activation to weak signals that could be considered a form of self-recognition and/or unwanted $\mathrm{B}$ cell responses under the appropriate circumstances ${ }^{40}$. Our results suggest that Gal-1 bound to $\lambda 5$-UR would help recruitment of $\alpha 2,3$ sialylated receptors at the pre-B synapse. In addition, although our experimental setup using MAL II lectin is not a physiological condition, we showed that clustering of a broad range of $\alpha 2,3$ sialylated receptors lead to pre-B cell death and that Gal-1/ $\lambda 5$-UR complex is able to disrupt the clustered sialylated receptors thus promoting pre-B cell survival (Fig. 3). Similarly to the CD22 dependent regulation of BCR signaling, it is tempting to propose that MAL II in our experiments would mimic a physiological receptor which would trigger specific cellular responses (Fig. 6b). The presence of Gal-1 bound to the pre-BCR would disrupt this clustering by recruiting specific $\alpha 2,3$ sialylated receptors at the pre-B synapse to activate proper signaling (Fig. 6b). Indeed, restricted receptor segregation into membrane microdomains would result in a homogenous platform suitable for efficient pre-BCR signaling leading to proliferation and survival. In line with this model of pre-BCR activation, it has been previously observed that Gal-1 binding resulted in the formation of large highly immobile pre-BCR aggregates at the pre-B cell surface ${ }^{41}$. Moreover, the clustering of specific glycoproteins and/or glycolipids could generate mechanical stress which translates into membrane curvature necessary for pre-BCR internalization following cell signaling. This model is strongly supported by previous evidence showing that another Galectin, the chimeric Galectin-3 (Gal-3), is able to mediate endocytic invaginations by helping the clustering of cargo proteins and glycosphingolipids ${ }^{39,40}$. Overall, our study reveals that the Gal-1/pre-BCR interaction is part of the glycome decoding mechanism on the surface of pre-B cells and 
would aim to re-orchestrate receptors localization to ensure cell signaling regulation and proper B cell development.

At the structural level, upon $\lambda 5$-UR interaction, dynamic fluctuations throughout Gal-1 occurs with an overall increased rigidity which locks Gal-1 into a conformation prone to interact with specific glycans and exclude others. This allostery-based mechanism of regulation for Gal$1 /$ glycan interactions leads to specific selection of $\alpha 2,3$ sialylated glycoconjugates at the pre-B cell surface. Allostery based phenomena have been previously shown for Gal-1 binding to synthetic inhibitor molecules designed to target Gal-1 interactions ${ }^{42-44}$. In addition, studies on glycan recognition by Gal-1 showed that sugar binding affected residues far from the CBS and described significant changes in the dynamics of the protein thus evidencing Gal-1 conformational plasticity and allostery upon glycan interaction ${ }^{45}$. These data, together with our study, emphasize the existence of intramolecular communication pathways encoded within Gal-1 structure which link glycan binding to dimer interface but also to protein interaction. Rather than a simple modification of ligand targeting, these dynamic changes result in Gal-1 conversion from exo- to endo-type lectin. To the best of our knowledge, this result is the first example of such conversion dictating the glycan preference of a Galectin. Gal-1 bound to $\lambda 5$-UR is able to interact with terminal and internal galactose like the tandemrepeat Gal- $8^{21}$. Tandem-repeat Galectins (Galectins with two CRDs linked by a flexible linker) are known to be more potent in triggering cellular responses ${ }^{46}$, therefore $\lambda 5$-UR induced conversion might increase Gal-1 efficiency at the pre-B cell surface through the formation of higher-order multimers as seen for tandem-repeat Galectins ${ }^{46}$.

Beyond the pre-BCR case, our results raise a fundamental question: is there a universal mechanism of allosteric modulation of glycan binding that is conserved across all Galectins through binding to non-glycosylated protein partners? Indeed, there are increasing evidence for direct protein interactions with Galectins ${ }^{16-18,47}$. We also demonstrated that CXCL4 
interacts with Gal-1 and control its glycan binding activities at the base of the immunoregulatory function of galectins ${ }^{47}$. The pre-BCR case and these latter examples all involve the three different Galectin subfamilies (prototype, chimera and tandem-repeat) ${ }^{4}$. Further structural, cellular and glycomic studies of these new complexes are needed to demonstrate a universal allosteric mechanism of regulation for Galectins functions. Moreover, taking into account Galectins involvement in many crucial pathologies such as cancer ${ }^{6,48}$ and inflammation $^{49}$ or infection by pathogens ${ }^{7}$, the discovery of this selectivity switch should also increase the potential to develop molecules modulating Gal-1 interactions and function in specific pathological situations.

\section{Methods}

Protein production and purification: ${ }^{15} \mathrm{~N}$-labeled Gal-1 has been produced and purified as previously described ${ }^{50}$. Protein purity was checked using SDS-polyacrylamide gel electrophoresis.

Peptide synthesis: The $\lambda 5$-UR (residue 22-45) and $\lambda 5$-UR-L26A-W30A peptides were chemically synthesized and purchased from Schafer-N, Copenhagen, Denmark.

Membrane vesicle preparation: The murine stromal cell line OP9 ${ }^{51}$ used in this study corresponds to OP9 cells whose Gal-1 expression was decreased by $75 \%$ using a Gal-1 specific shRNA $\left(\operatorname{shGAL1}^{52}\right)$. The cells were cultivated in MEM $\alpha$-Glutamax, $20 \%$ fetal calf serum (FCS), $100 \mathrm{U} \cdot \mathrm{ml}^{-1}$ penicillin and $100 \mu \mathrm{g} \cdot \mathrm{ml}^{-1}$ streptomycin. The cells were mechanically detached from the dishes using cell scrapers to avoid the use of trypsine. The human pre-B cell line Nalm6 $6^{53}$ was grown in RPMI, $10 \%$ fetal calf serum, $100 \mathrm{U}^{-1} \mathrm{~m}^{-1}$ penicillin, $100 \mu \mathrm{g} \cdot \mathrm{ml}^{-1}$ streptomycin and $50 \mu \mathrm{M} \beta$-mercaptoethanol. Upon centrifugation at 450g during 5 minutes at room temperature, cells were re-suspended with PBS (Phosphate Buffer Saline) $1 \mathrm{X}\left(137 \mathrm{mM} \mathrm{NaCl} \mathrm{pH} 7.4,2.7 \mathrm{mM} \mathrm{KCl}, 4.3 \mathrm{mM} \mathrm{Na} 2 \mathrm{HPO}_{4}, 1.47 \mathrm{mM}\right.$ 
$\mathrm{KH}_{2} \mathrm{PO}_{4}$ ). Cells were vesiculated by sonication and subsequently centrifuged at $100,000 \mathrm{~g}$ for $1 \mathrm{~h}$ at $4^{\circ} \mathrm{C}$ to collect membrane vesicles. Vesicles were resuspended in $20 \mathrm{mM} \mathrm{KPO} 4 \mathrm{pH} 5.2$ buffer. Protein concentration is then estimated using the Pierce ${ }^{\mathrm{TM}}$ BCA protein assay kit.

Negative staining electronic microscopy: Experiments were performed using samples of pre-B or stromal cell vesicles placed on glow-discharged carbon-coated grid during $60 \mathrm{~s}$ and the excess solution was removed by touching a piece of filter paper to the side of the grid. After the adsorption of the sample on the support, the grid was washed by being placed on the surface of a drop of deionized water. This step was repeated three times before the grid was blotted dry with filter paper. Three drops of filtered $(0.02 \mu \mathrm{m}$ filter $) 2 \%$ uranyl formate solution were applied on the sample during 3 minutes for each drop before the excess solution was removed by blotting similarly between each drop application. The grid was then air dried. The uranyl formate being light-sensitive, the filter syringe was wrapped in aluminum foil to reduced light exposition. Images were recorded on an FEI Tecnai 200-kV electron microscope.

PNGase F and O-glycosidase cell treatments: The cells were resuspended in $50 \mathrm{mM}$ sodium phosphate buffer, centrifuged 5 minutes $(450 g)$ at room temperature and the supernatant was discarded. This step was repeated twice to allow the removal of the cell media growth. The PNGase F (New England Biolabs) and O-glycosidase (New England Biolabs) enzymes were added (50000 $\mathrm{U}$ and $1800000 \mathrm{U}$, respectively) to 10 million resuspended stromal cells and incubated overnight at $37^{\circ} \mathrm{C}$. After centrifugation 5 minutes at $450 \mathrm{~g}$ at room temperature, the treated cells were washed twice with PBS buffer. Protein concentration is then estimated before storage at $-80^{\circ} \mathrm{C}$. The control of the treatment consisted in incubating 1 hour the treated and untreated cells with His-tagged Gal-1 (His-Gal-1) followed by washing steps. The binding of the His-Gal-1 to treated and untreated cells was assessed by Western Blot. 
Cell viability assays: Before treatments, cells were starved with RPMI 0,5\% FCS, $100 \mathrm{U} \cdot \mathrm{ml}^{-1}$ penicillin and $100 \mu \mathrm{g} \cdot \mathrm{ml}^{-1}$ streptomycin during $1 \mathrm{~h} 30$ at $37^{\circ} \mathrm{C}, 5 \% \mathrm{CO}_{2}$. After two washes with cold PBS, $1.10^{6}$ cells were treated with $10 \mu \mathrm{g} / \mathrm{mL}$ MAL II lectin (Eurobio, L1260-2) alone or with $10 \mu \mathrm{g} / \mathrm{mL}$ Galectin- 1 or with $10 \mu \mathrm{g} / \mathrm{mL}$ Galectin- 1 and $100 \mu \mathrm{g} / \mathrm{mL} \lambda 5$-UR peptide (Schafer-N) during 30min on ice. Then, cells were centrifugated 5 min, $450 \mathrm{~g}$ at $4^{\circ} \mathrm{c}$ and the pellet was resuspended with cold PBS. Pre-B Cell viability was assessed using trypan blue dye exclusion test ${ }^{54}$ and the CellTiter-Glo® assay (Promega, G7570). For the CellTiterGlo assay, CTG reagent was mixed at a 1:1 volume ratio with cells on a plastic 96-well plate according to the manufacturer's protocol and luminescence measurements were completed using the TECAN (Männedorf, Suisse).

NMR spectroscopy: All NMR experiments have been recorded on a $600 \mathrm{MHz}$ Bruker $^{\mathrm{TM}}$ AVANCE III spectrometer equipped with a TCI cryoprobe at $303 \mathrm{~K}$. All samples were in 20 $\mathrm{mM}$ phosphate buffer at $\mathrm{pH}$ 5.2. All NMR experiments were recorded using $5 \mathrm{~mm}$ NMR tubes except experiments on ${ }^{13} \mathrm{C}$-labelled SdiLN which were recorded using $3 \mathrm{~mm}$ NMR tubes. All spectra were analyzed using ccpNMR Analysis software ${ }^{55}$, and the dynamics spectra experiments were analyzed using the Bruker ${ }^{\mathrm{TM}}$ Dynamic Center software.

NMR titrations: The NMR titrations of Gal-1/vesicles interactions were performed using a series of $2 \mathrm{D}{ }^{1} \mathrm{H},{ }^{15} \mathrm{~N}$ HSQC NMR spectra recorded on a sample of purified ${ }^{15} \mathrm{~N}$-labelled Gal-1 at $200 \mu \mathrm{M}$ concentration and increasing amounts of cellular vesicles. Final titration points for pre-B and stromal cell vesicles correspond to the addition of vesicles containing $2 \mathrm{mg}$ proteins. To obtain this amount of protein 100 million pre-B and 10 million stromal cells have been used. The same series were performed in the presence of $900 \mu \mathrm{M} \lambda$ 5-UR peptide. NMR data were analyzed using Gal-1 NMR resonance assignment previously published $^{56}$. The chemical shift perturbations for each resonance were calculated using the equation: 
$\Delta \delta_{\mathrm{obs}}=\left[\Delta \delta_{\mathrm{HN}^{2}}+\left(\Delta \delta_{\mathrm{N}}^{2} / 25\right)\right]^{1 / 2}$ where $\Delta \delta_{\mathrm{HN}}$ and $\Delta \delta_{\mathrm{N}}$ are, respectively, the proton and nitrogen chemical shift variations of each residue.

STD experiments: $2 \mathrm{D}{ }^{1} \mathrm{H}_{-}{ }^{13} \mathrm{C}$ STD HSQC experiments were acquired with a saturation time of 2 seconds with 256 increments of 128 scans each. The STD experiments were performed using 100:1 SdiLN/Gal-1 and 100:1:3 SdiLN/Gal-1/25-UR molar ratio samples at $1 \mathrm{mM}$ concentration for SdiLN. For 1D and 2D STD spectra the on-resonance irradiation was at 6.7 ppm and the off resonance irradiation at $20 \mathrm{ppm}$ and were performed with a saturation time of $2 \mathrm{~s}$.

NMR relaxation measurements: Dynamics of ${ }^{15} \mathrm{~N}-\mathrm{Gal}-1$ free and bound to $\lambda 5$-UR peptide or Anginex peptide was obtained using NMR experiments acquired at $60.81 \mathrm{MHz}$ for the ${ }^{15} \mathrm{~N}$ frequency. The longitudinal $\left(T_{1}\right)$, transverse $\left(T_{2}\right)$, and ${ }^{1} \mathrm{H}-{ }^{15} \mathrm{~N}$-heteronuclear NOE spin relaxation times for the backbone ${ }^{15} \mathrm{~N}$ atoms of Gal-1 free and bound to $\lambda 5$-UR peptide or Anginex peptide were collected at $303 \mathrm{~K}$ using the well-established NMR pulse sequences described previously ${ }^{57-59}$. The $T_{1}$ and $T_{2}$ relaxation times were measured using the following series of the delays: $10,20,50,100,200,300,400,600,800,1000,1500$ and $2000 \mathrm{~ms}$ for $T_{1}$ and 17.6, 35.2, 52.8, 70.4, 88.0, 105.6, 123.2, 140.8, 158.4 and $176 \mathrm{~ms}$ for $T_{2}$. The relaxation rates $\mathrm{R} 1$ and $\mathrm{R} 2$ were calculated by fitting the decay curves to a two-parameter single exponential decay function using the Bruker software Dynamic center. ${ }^{1} \mathrm{H}-{ }^{15} \mathrm{~N}$ heteronuclear NOE were measured from the HSQC and the value were calculated as the peak intensity ratio with or without amide proton saturation.

General synthesis procedure for N-Acetylneuraminyl- $\alpha-2,3-D-G a l a c t o p y r a n o s y l-\beta-1,4-2-$

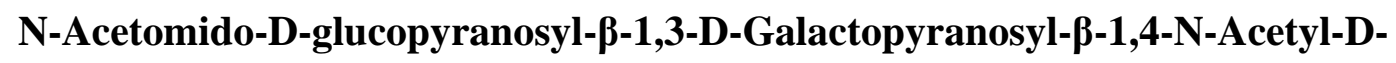

Glucosamine (SdiLN): Materials. All non-stable isotope labeled nucleotides, nucleotidesugars, enzymes, and chemicals were purchased from Sigma-Aldrich (St. Louis, MO), unless 
otherwise stated. Ni-NTA Agarose was purchased from Qiagen (Santa Clarita, CA), and BioGel P2 from Bio-Rad (Hercules, CA). Glucose $\left({ }^{13} \mathrm{C}_{6}, 99 \%\right)$ was purchased from Cambridge Isotope Laboratories (Andover, MA). The enzymes used in the synthesis of SdiLN were prepared according published methods: GalE ${ }^{60}, \mathrm{HP}-39^{61}, \mathrm{PmST}^{62}$. The UDP-Glucose $\left({ }^{13} \mathrm{C}_{6}\right.$, 99\%) was prepared by previously published methods ${ }^{63}$.

D-Galactopyranosyl- $\beta$-1,4-N-Acetyl-D-Glucosamine (Supplementary Fig. 6a, compound 2).

To a reaction mixture $(400 \mu \mathrm{L})$ containing $40 \mathrm{mM}$ N-Acetyl-D-Glucosamine (Supplementary Fig. $6 a$, compound 1, $16 \mu \mathrm{mol}$ ), $48 \mathrm{mM}$ UDP-Glc, $20 \mathrm{mM} \mathrm{MnCl}_{2}$ in $100 \mathrm{mM}$ Sodium Cacodylate Buffer (pH 7.5), $\beta 4 \mathrm{GalT} 1$ (1 U) and GalE (10 U) were added and incubated overnight at $37{ }^{\circ} \mathrm{C}$. The completed reaction, as evident by TLC, was centrifuged and the supernatant subjected to gel filtration on Bio-Gel P-2 $(1 \times 120 \mathrm{~cm}$ column, in $100 \mathrm{mM}$ $\mathrm{NH}_{4} \mathrm{HCO}_{3}$ solution). Fractions containing 2 were combined and lyophilized to produce a white amorphous solid ( $12.8 \mu \mathrm{mol}, \sim 80 \%$ isolated yield $)$.

\section{2-Acetomido-D-Glucopyranosyl- $\beta$-1,3-D-Galactopyranosyl- $\beta$-1,4-N-Acetyl-D-Glucosamine}

(Supplementary Fig. 6a, compound 3). To a reaction mixture $(640 \mu \mathrm{L})$ containing $10 \mathrm{mM}$ of 2 (6.4 $\mu \mathrm{mol}), 12 \mathrm{mM}$ UDP-GlcNAc, $25 \mathrm{mM} \mathrm{KCl}, 20 \mathrm{mM} \mathrm{MgCl} 2,1 \mathrm{mM}$ DTT, in $100 \mathrm{mM}$ Sodium Cacodylate Buffer (pH 7.5), HP-39 (10 U) was added and incubated overnight at 37 ${ }^{\circ} \mathrm{C}$. The completed reaction, as evident by TLC, was centrifuged and the supernatant subjected to gel filtration on Bio-Gel P-2 (1×120 cm column, in $100 \mathrm{mM} \mathrm{NH} 4 \mathrm{HCO}_{3}$ solution). Fractions containing 3 were combined and lyophilized to produce a white amorphous solid ( $4.5 \mu \mathrm{mol}, \sim 70 \%$ isolated yield).

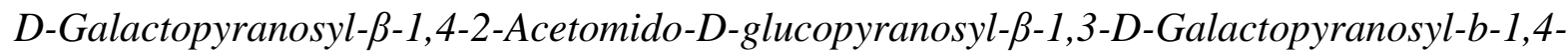
N-Acetyl-D-Glucosamine (Supplementary Fig. 6a, compound 4). To a reaction mixture (100 $\mu \mathrm{L}$ ) containing $40 \mathrm{mM}$ of $3(4 \mu \mathrm{mol}), 48 \mathrm{mM}$ UDP-Glc, $20 \mathrm{mM} \mathrm{MnCl} 2$ in $100 \mathrm{mM}$ Sodium 
Cacodylate Buffer (pH 7.5), $\beta 4 \mathrm{GalT1}$ (1 U) and GalE (10 U) were added and incubated overnight at $37{ }^{\circ} \mathrm{C}$. The completed reaction, as evident by TLC, was centrifuged and the supernatant subjected to gel filtration on Bio-Gel P-2 $(1 \times 120 \mathrm{~cm}$ column, in $100 \mathrm{mM}$ $\mathrm{NH}_{4} \mathrm{HCO}_{3}$ solution). Fractions containing 4 were combined and lyophilized to produce a white amorphous solid ( $3.2 \mu \mathrm{mol}, \sim 80 \%$ isolated yield).

$N$-Acetylneuraminyl- $\alpha$-2,3-D-Galactopyranosyl- $\beta$-1,4-2-Acetomido-D-glucopyranosyl- $\beta$-1,3-

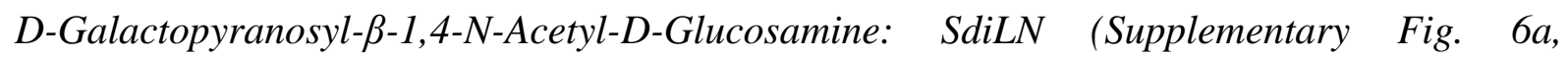
compound 5). To a reaction mixture $(80 \mu \mathrm{L})$ containing $20 \mathrm{mM}$ of $4(1.6 \mu \mathrm{mol}), 24 \mathrm{mM}$ CMP-Neu5Ac, $20 \mathrm{mM} \mathrm{MnCl} 2$ in 100 mM Sodium Cacodylate Buffer (pH 7.5), PmST1 (1 U) was added and incubated overnight at $37^{\circ} \mathrm{C}$. The completed reaction, as evident by TLC, was centrifuged and the supernatant subjected to gel filtration on Bio-Gel P-2 $(1 \times 120 \mathrm{~cm}$ column, in $100 \mathrm{mM} \mathrm{NH} \mathrm{NCO}_{3}$ solution). Fractions containing 5 (SdiLN) were combined and lyophilized to produce a white amorphous solid $(\sim 0.56 \mu \mathrm{mol}, \sim 35 \%$ isolated yield $)$.

SdiLN resonance assignment: ${ }^{1} \mathrm{H}$ and ${ }^{13} \mathrm{C}$ NMR resonance assignments of SdiLN have been performed using 2D ${ }^{1} \mathrm{H},{ }^{13} \mathrm{C}$ HSQC, 2D ${ }^{1} \mathrm{H},{ }^{13} \mathrm{C}$ HSQC-TOCSY, 2D ${ }^{1} \mathrm{H},{ }^{1} \mathrm{H}$-TOCSY, 2D ${ }^{1} \mathrm{H}$, ${ }^{1} \mathrm{H}$-ROESY and 2D ${ }^{1} \mathrm{H},{ }^{1} \mathrm{H}-\mathrm{COSY}$ experiments. A sample of SdiLN with ${ }^{13} \mathrm{C}$ - labeled Galactoses was used for recording 2D ${ }^{1} \mathrm{H},{ }^{13} \mathrm{C}$ HSQC and 2D ${ }^{1} \mathrm{H},{ }^{13} \mathrm{C}$ HSQC-TOCSY.

\section{Acknowledgments}

This work was funded by grants from the Agence Nationale de la Recherche (ANR-16-CE110005-01), the Centre National de la Recherche Scientifique and the Aix-Marseille Université. The authors thank the participation of the Protein-Glycan Interaction Resource of the CFG (supporting grant R24 GM098791) and the National Center for Functional Glycomics (NCFG) at Beth Israel Deaconess Medical Center, Harvard Medical School (supporting grant P41 GM103694). This work has benefited from the facilities and expertise of the 
Platform for Microscopy of the Mediterranean institute of microbiology, the authors thank especially Artemis Kostas.

Author Contributions: P.T. and L.E. designed research. P.T., B.S., A.C., O.B., Q.C., L.G.S., S.J.M. and L.E. performed research. J.R.W contributed new reagents. P.T., C.S.K. and L.E. analyzed data. L.E. wrote the manuscript. 


\section{References}

1. Varki, A. Biological roles of glycans. Glycobiology 27, 3-49 (2017).

2. Laine, R. A. Invited Commentary: A calculation of all possible oligosaccharide isomers both branched and linear yields $1.05 \times 1012$ structures for a reducing hexasaccharide: the Isomer Barrier to development of single-method saccharide sequencing or synthesis systems. Glycobiology 4, 759-767 (1994).

3. André, S., Kaltner, H., Manning, J. C., Murphy, P. V. \& Gabius, H.-J. Lectins: Getting Familiar with Translators of the Sugar Code. Molecules 20, 1788-1823 (2015).

4. Johannes, L., Jacob, R. \& Leffler, H. Galectins at a glance. Journal of Cell Science 131, jcs208884 (2018).

5. Leffler, H. Galectins structure and function--a synopsis. Results Probl Cell Differ 33, 57-83 (2001).

6. Girotti, M. R., Salatino, M., Dalotto-Moreno, T. \& Rabinovich, G. A. Sweetening the hallmarks of cancer: Galectins as multifunctional mediators of tumor progression. Journal of Experimental Medicine 217, e20182041 (2019).

7. Vasta, G. R. Galectins in Host-Pathogen Interactions: Structural, Functional and Evolutionary Aspects. in Lectin in Host Defense Against Microbial Infections (ed. Hsieh, S.L.) 169-196 (Springer, 2020). doi:10.1007/978-981-15-1580-4_7.

8. Nio-Kobayashi, J. \& Itabashi, T. Galectins and Their Ligand Glycoconjugates in the Central Nervous System Under Physiological and Pathological Conditions. Frontiers in Neuroanatomy 15, 74 (2021).

9. Wan, L., Hsu, Y.-A., Wei, C.-C. \& Liu, F.-T. Galectins in allergic inflammatory diseases. Molecular Aspects of Medicine 79, 100925 (2021).

10. van der Hoeven, N. W. et al. The emerging role of galectins in cardiovascular disease. Vascular Pharmacology 81, 31-41 (2016).

11. Sethi, A., Sanam, S. \& Alvala, M. Non-carbohydrate strategies to inhibit lectin proteins with special emphasis on galectins. European Journal of Medicinal Chemistry 222, 113561 (2021).

12. Bertuzzi, S., Quintana, J. I., Ardá, A., Gimeno, A. \& Jiménez-Barbero, J. Targeting Galectins With Glycomimetics. Frontiers in Chemistry 8, 593 (2020).

13. Laaf, D., Bojarová, P., Elling, L. \& Křen, V. Galectin-Carbohydrate Interactions in Biomedicine and Biotechnology. Trends in Biotechnology 37, 402-415 (2019). 
14. Brewer, C. Clusters, bundles, arrays and lattices: novel mechanisms for lectinsaccharide-mediated cellular interactions. Current Opinion in Structural Biology 12, 616-623 (2002).

15. Bonzi, J. et al. Pre-B cell receptor binding to galectin-1 modifies galectin1/carbohydrate affinity to modulate specific galectin-1/glycan lattice interactions. Nat Commun 6, 6194 (2015).

16. Advedissian, T. et al. E-cadherin dynamics is regulated by galectin-7 at epithelial cell surface. Sci Rep 7, 17086 (2017).

17. Daley, D. et al. Dectin 1 activation on macrophages by galectin 9 promotes pancreatic carcinoma and peritumoral immune tolerance. Nat Med 23, 556-567 (2017).

18. Eckardt, V. et al. Chemokines and galectins form heterodimers to modulate inflammation. EMBO Rep 21, e47852 (2020).

19. Gauthier, L., Rossi, B., Roux, F., Termine, E. \& Schiff, C. Galectin-1 is a stromal cell ligand of the pre-B cell receptor (BCR) implicated in synapse formation between pre-B and stromal cells and in pre-BCR triggering. PNAS 99, 13014-13019 (2002).

20. Nagae, M. \& Yamaguchi, Y. Three-Dimensional Structural Aspects of ProteinPolysaccharide Interactions. International Journal of Molecular Sciences 15, 3768-3783 (2014).

21. Moure, M. J. et al. Selective 13C-Labels on Repeating Glycan Oligomers to Reveal Protein Binding Epitopes through NMR: Polylactosamine Binding to Galectins. Angewandte Chemie International Edition 60, 18777-18782 (2021).

22. Rossi, B., Espeli, M., Schiff, C. \& Gauthier, L. Clustering of Pre-B Cell Integrins Induces Galectin-1-Dependent Pre-B Cell Receptor Relocalization and Activation. The Journal of Immunology 177, 796-803 (2006).

23. Winkler, T. H. \& Mårtensson, I.-L. The Role of the Pre-B Cell Receptor in B Cell Development, Repertoire Selection, and Tolerance. Frontiers in Immunology 9, 2423 (2018).

24. Elantak, L. et al. Structural Basis for Galectin-1-dependent Pre-B Cell Receptor (PreBCR) Activation *. Journal of Biological Chemistry 287, 44703-44713 (2012).

25. Houzelstein, D. et al. Phylogenetic Analysis of the Vertebrate Galectin Family. Molecular Biology and Evolution 21, 1177-1187 (2004).

26. Ishima, R. \& Torchia, D. A. Protein dynamics from NMR. Nat Struct Biol 7, 740-743 (2000).

27. Perdicchio, M. et al. Sialic acid-modified antigens impose tolerance via inhibition of T-cell proliferation and de novo induction of regulatory T cells. PNAS 113, 3329-3334 (2016). 
28. Courtney, A. H., Puffer, E. B., Pontrello, J. K., Yang, Z.-Q. \& Kiessling, L. L.

Sialylated multivalent antigens engage CD22 in trans and inhibit B cell activation. PNAS 106, 2500-2505 (2009).

29. Mayer, M. \& Meyer, B. Characterization of Ligand Binding by Saturation Transfer Difference NMR Spectroscopy. Angewandte Chemie International Edition 38, 1784-1788 (1999).

30. Mayer, M. \& Meyer, B. Group Epitope Mapping by Saturation Transfer Difference NMR To Identify Segments of a Ligand in Direct Contact with a Protein Receptor. J. Am. Chem. Soc. 123, 6108-6117 (2001).

31. Stowell, S. R. et al. Human galectin-1 recognition of poly-N-acetyllactosamine and chimeric polysaccharides. Glycobiology 14, 157-167 (2004).

32. Di Virgilio, S., Glushka, J., Moremen, K. \& Pierce, M. Enzymatic synthesis of natural and $13 \mathrm{C}$ enriched linear poly-N-acetyllactosamines as ligands for galectin-1. Glycobiology $\mathbf{9}$, 353-364 (1999).

33. Lajoie, P. et al. Plasma membrane domain organization regulates EGFR signaling in tumor cells. Journal of Cell Biology 179, 341-356 (2007).

34. Pace, K. E., Lee, C., Stewart, P. L. \& Baum, L. G. Restricted Receptor Segregation into Membrane Microdomains Occurs on Human T Cells During Apoptosis Induced by Galectin-1. The Journal of Immunology 163, 3801-3811 (1999).

35. Bednar, K. J. et al. Human CD22 Inhibits Murine B Cell Receptor Activation in a Human CD22 Transgenic Mouse Model. The Journal of Immunology 199, 3116-3128 (2017).

36. Nguyen, J. T. et al. CD45 Modulates Galectin-1-Induced T Cell Death: Regulation by Expression of Core 2 O-Glycans. The Journal of Immunology 167, 5697-5707 (2001).

37. Sacchettini, J. C., Baum, L. G. \& Brewer, C. F. Multivalent Protein-Carbohydrate Interactions. A New Paradigm for Supermolecular Assembly and Signal Transduction. Biochemistry 40, 3009-3015 (2001).

38. O'Keefe, T. L., Williams, G. T., Davies, S. L. \& Neuberger, M. S. Hyperresponsive B Cells in CD22-Deficient Mice. Science (1996) doi:10.1126/science.274.5288.798.

39. Nanoscale organization and dynamics of the siglec CD22 cooperate with the cytoskeleton in restraining BCR signalling. The EMBO Journal 35, 258-280 (2016).

40. Enterina, J. R., Jung, J. \& Macauley, M. S. Coordinated roles for glycans in regulating the inhibitory function of CD22 on B cells. Biomedical Journal 42, 218-232 (2019).

41. Erasmus, M. F. et al. Dynamic pre-BCR homodimers fine-tune autonomous survival signals in B cell precursor acute lymphoblastic leukemia. Science Signaling (2016) doi:10.1126/scisignal.aaf3949. 
42. Dings, R. P. M. et al. Antitumor Agent Calixarene 0118 Targets Human Galectin-1 as an Allosteric Inhibitor of Carbohydrate Binding. J. Med. Chem. 55, 5121-5129 (2012).

43. Dings, R. P. M. et al. Structure-Based Optimization of Angiostatic Agent 6DBF7, an Allosteric Antagonist of Galectin-1. J Pharmacol Exp Ther 344, 589-599 (2013).

44. Dings, R. P. M., Miller, M. C., Griffin, R. J. \& Mayo, K. H. Galectins as Molecular Targets for Therapeutic Intervention. International Journal of Molecular Sciences 19, 905 (2018).

45. Bertuzzi, S. et al. Unravelling the Time Scale of Conformational Plasticity and Allostery in Glycan Recognition by Human Galectin-1. Chemistry - A European Journal 26, 15643-15653 (2020).

46. Earl, L. A., Bi, S. \& Baum, L. G. Galectin multimerization and lattice formation are regulated by linker region structure. Glycobiology 21, 6-12 (2011).

47. Sanjurjo, L. et al. Chemokines modulate glycan binding and the immunoregulatory activity of galectins. Commun Biol 4, 1-11 (2021).

48. Elola, M. T. et al. Galectins: Multitask signaling molecules linking fibroblast, endothelial and immune cell programs in the tumor microenvironment. Cellular Immunology 333, 34-45 (2018).

49. Morosi, L. G. et al. Control of intestinal inflammation by glycosylation-dependent lectin-driven immunoregulatory circuits. Science Advances (2021)

doi:10.1126/sciadv.abf8630.

50. Pace, K. E., Hahn, H. P. \& Baum, L. G. Preparation of Recombinant Human Galectin1 and Use in T-Cell Death Assays. in Methods in Enzymology vol. 363 499-518 (Academic Press, 2003).

51. Kodama, H., Nose, M., Niida, S., Nishikawa, S. \& Nishikawa, S. Involvement of the c-kit receptor in the adhesion of hematopoietic stem cells to stromal cells. Exp Hematol 22, 979-984 (1994).

52. Espeli, M., Mancini, S. J. C., Breton, C., Poirier, F. \& Schiff, C. Impaired B-cell development at the pre-BII-cell stage in galectin-1-deficient mice due to inefficient preBII/stromal cell interactions. Blood 113, 5878-5886 (2009).

53. Hurwitz, R. et al. Characterization of a leukemic cell line of the pre-B phenotype. International Journal of Cancer 23, 174-180 (1979).

54. Strober, W. Trypan Blue Exclusion Test of Cell Viability. Current Protocols in Immunology 111, A3.B.1-A3.B.3 (2015).

55. Vranken, W. F. et al. The CCPN data model for NMR spectroscopy: development of a software pipeline. Proteins 59, 687-696 (2005). 
56. Nesmelova, I. V., Pang, M., Baum, L. G. \& Mayo, K. H. 1H, 13C, and 15N backbone and side-chain chemical shift assignments for the $29 \mathrm{kDa}$ human galectin-1 protein dimer. Biomol NMR Assign 2, 203-205 (2008).

57. Barbato, G., Ikura, M., Kay, L. E., Pastor, R. W. \& Bax, A. Backbone dynamics of calmodulin studied by $15 \mathrm{~N}$ relaxation using inverse detected two-dimensional NMR spectroscopy: the central helix is flexible. Biochemistry 31, 5269-5278 (1992).

58. Kay, L. E., Torchia, D. A. \& Bax, A. Backbone dynamics of proteins as studied by $15 \mathrm{~N}$ inverse detected heteronuclear NMR spectroscopy: application to staphylococcal nuclease. Biochemistry 28, 8972-8979 (1989).

59. Farrow, N. A. et al. Backbone dynamics of a free and phosphopeptide-complexed Src homology 2 domain studied by 15N NMR relaxation. Biochemistry 33, 5984-6003 (1994).

60. Chen, X., Zhang, W., Wang, J., Fang, J. \& Wang, P. G. Production of $\alpha$-Galactosyl Epitopes via Combined Use of Two Recombinant Whole Cells Harboring UDP-Galactose 4-

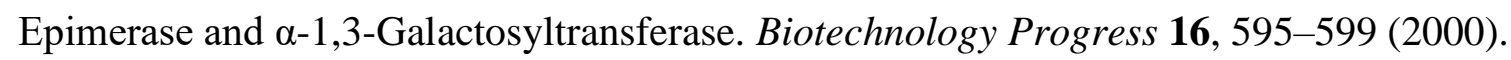

61. Peng, W. et al. Helicobacter pylori $\beta 1,3-\mathrm{N}$-acetylglucosaminyltransferase for versatile synthesis of type 1 and type 2 poly-LacNAcs on N-linked, O-linked and I-antigen glycans. Glycobiology 22, 1453-1464 (2012).

62. Yu, C.-C. et al. Site-Specific Immobilization of Enzymes on Magnetic Nanoparticles and Their Use in Organic Synthesis. Bioconjugate Chem. 23, 714-724 (2012).

63. Lee, H. C., Lee, S.-D., Sohng, J. K. \& Liou, K. One-pot enzymatic synthesis of UDPD-glucose from UMP and glucose-1-phosphate using an ATP regeneration system. J Biochem Mol Biol 37, 503-506 (2004).

64. López-Lucendo, M. F. et al. Growth-regulatory Human Galectin-1: Crystallographic Characterisation of the Structural Changes Induced by Single-site Mutations and their Impact on the Thermodynamics of Ligand Binding. Journal of Molecular Biology 343, 957-970 (2004).

65. Neelamegham, S. et al. Updates to the Symbol Nomenclature for Glycans guidelines. Glycobiology 29, 620-624 (2019).

66. Meyer, S. J., Linder, A. T., Brandl, C. \& Nitschke, L. B Cell Siglecs-News on Signaling and Its Interplay With Ligand Binding. Frontiers in Immunology 9, (2018). 


\section{Figure caption}

Figure 1. Gal-1 binding to pre-B and stromal cell surface ligands. (a) Strategy for on-cell NMR study of Gal-1 binding to pre-B and stromal cell vesicles. Cells are cultured as described in the Methods section, then sonicated to generate the vesicles which are collected after ultracentrifugation cycles. Vesicles are finally incubated with ${ }^{15} \mathrm{~N}$-labelled Gal-1 to proceed to NMR experiment recording. (b) A histogram showing CSDs upon addition into ${ }^{15} \mathrm{~N}$-labelled Gal-1 sample of membrane vesicles extracted from 100 million pre-B cells (green bars), 10 million stromal cells (orange bars) and 10 million PNGaseF and Oglycosidase treated stromal cells (blue bars). (c) and (d) Residues whose resonances have considerable CSDs upon (c) pre-B and (d) stromal vesicles addition are mapped onto Gal-1 homodimer surface structure (PDB: $1 \mathrm{GZW}^{64}$ ) and colored from grey (no significant CSD) to red (highest CSD) as indicated in the gradient scale. The upper panel shows the CBS view and the lower panel the backside view after a $180^{\circ}$ rotation. CBS subsites are framed and labeled on one monomer (only one CBS is entirely visible due to the homodimer symmetry) using the following color-code: Subsite A: light green, B: brown, C: purple, D: cyan, E: magenta. Dashed lines represent the Gal-1 dimer interface.

Figure 2. Impact of $\lambda 5$-UR interaction on Gal-1 binding to pre-B cell vesicles. (a) A histogram showing CSDs of Gal-1 resonances upon addition of pre-B cell vesicles and $\lambda 5$-UR (magenta bars), and of pre-B cell vesicles and $\lambda 5$-UR-L26A-W30A (grey bars). (b) CSDs, calculated by comparing chemical shift resonances of Gal-1 free and Gal-1 bound pre-B cell vesicles and $\lambda 5$-UR, are reported on Gal-1 surface and colored as in Fig. 1c. The $\lambda 5$-UR binding site is framed in blue and labeled. (c) Chemical shift perturbations of selected Gal-1 resonances upon addition of pre-B cell vesicles (green) followed by $\lambda 5$-UR addition (magenta). N56, N50, E74 and V76 resonances show chemical shift perturbations in the 
presence of pre-B cell vesicles but move back toward their initial Gal-1 free resonance position upon $\lambda 5$-UR addition. N33 and H52 resonances show perturbations only upon $\lambda 5$-UR interaction while being part of the CBS and not the $\lambda 5$-UR binding site. (d) CSDs observed upon addition of mixed pre-B and stromal cell vesicles, and $\lambda 5-\mathrm{UR}$ are reported on Gal-1 homodimer surface structure. As in Fig. 1, cell vesicles were extracted from 10 million and 100 million stromal and pre-B cells, respectively, which correspond for each sample to $2 \mathrm{mg}$ of total protein (1:1 protein ratio).

Figure 3. Binding of $\lambda \mathbf{5 - U R}$ mediate changes in Gal-1 internal dynamics. (a) Changes in order parameters, $\Delta S^{2}$, for Gal-1 residues upon $\lambda 5$-UR interaction. $\Delta S^{2}$ is given as $S^{2}$ (after peptide binding) $-S^{2}$ (before peptide binding), so positive $\Delta S^{2}$ values denote enhanced rigidity of the protein backbone upon peptide interaction. Residues from each CBS subsites are colored as indicated, residues involved in $\lambda 5$-UR interaction are colored in magenta, and broadened peaks are indicated with asterisk. (b) $\Delta S^{2}$ values are reported on Gal-1 homodimer structure, from blue (enhanced rigidity) to yellow (enhanced flexibility).

Figure 4. Gal-1 specifically targets $\alpha 2,3$ sialylated glycans at the pre-B cell surface when bound to $\lambda \mathbf{5 - U R}$. (a) Histogram plot showing Pre-B cell viability after incubation with MAL II, Gal-1 and $\lambda 5$-UR as indicated below the histogram. For each condition two bars are shown, the left bar corresponds to pre-B cell viability evaluated using CellTiter-Glo Luminescent Cell Viability Assay (Promega) and the right bar using Trypan blue exclusion test. Means and standard errors from three independent experiments are presented. Significant differences are represented as $* \mathrm{p}<0.05, * * \mathrm{p}<0.01$ and $* * * \mathrm{p}<0.001$. n.s indicates no significant differences. (b) Schematic illustrating MAL II induced pre-B cell death through clustering of $\alpha 2,3$ sialylated receptors. (c) The presence of Gal-1 does not perturb MAL II interactions and therefore pre-B cell death. (d) $\lambda 5$-UR binding to Gal-1 increases Gal-1 binding to $\alpha 2,3$ sialylated receptors containing $\beta$-galactosides, thus perturbing MAL II interactions and 
allowing Pre-B cell survival. Glycans are represented using the symbol nomenclature as indicated $^{65}$.

\section{Figure 5: $\lambda$ 5-UR binding to Gal-1 induces enhanced and additional intermolecular} contacts with $\alpha 2,3$ sialyl di-LacNAc (SdiLN). (a) ${ }^{1} \mathrm{H},{ }^{13} \mathrm{C}$ STD-HSQC spectrum (left) of $1 \mathrm{mM}$ SdiLN ${ }^{13} \mathrm{C}$-labeled on galactose moieties in the presence of $10 \mu \mathrm{M}$ Gal-1. Contribution to Gal-1 binding for each galactose as a percentage of the total STD signal observed is shown (right). (b) Overlay of ${ }^{1} \mathrm{H},{ }^{13} \mathrm{C}$ HSQC of labeled SdiLN (teal) and SdiLN in the presence of equimolar amount of Gal-1 (purple). Peaks disappearing are labeled (teal labels). Peaks appearing are also labeled (purple labels). (c) Variations are reported on the SdiLN chemical structure with unlabeled moieties greyed out. Teal stars indicate SdiLN C-H groups for which resonances disappear upon Gal-1 binding. Purple circles indicate SdiLN groups for which resonances appear upon Gal-1 binding. (d) Peak intensity loss observed on ${ }^{1} \mathrm{H},{ }^{15} \mathrm{~N}$ HSQC spectrum of Gal-1 after addition of SdiLN is reported on Gal-1 homodimer surface structure. A color gradient has been used to indicate the percentage of intensity loss as indicated on the gradient bar. CBS subsites are framed and labeled A to E. (e) to (h) Same as in (a) to (d) but after addition of $\lambda 5$-UR. (e) ${ }^{1} \mathrm{H},{ }^{13} \mathrm{C}$ STD-HSQC spectrum (left) of $1 \mathrm{mM}$ SdiLN ${ }^{13} \mathrm{C}$-labeled on galactose moieties in the presence of $10 \mu \mathrm{M}$ Gal-1 and $20 \mu \mathrm{M} \lambda$ 5-UR. Contribution to Gal-1 binding for each galactose as a percentage of the total STD signal observed is shown (right). (f) Overlay of ${ }^{1} \mathrm{H},{ }^{13} \mathrm{C}$ HSQC of labeled SdiLN bound to Gal-1 (purple) and after addition of $\lambda 5$-UR (orange). Peaks disappearing or showing decreased intensity are labeled and shown in orange. (g) Variations are reported on the SdiLN chemical structure. Large orange stars indicate SdiLN C-H groups for which resonances disappear upon Gal-1 and $\lambda 5$-UR binding. Small orange stars indicate groups showing decreased peak intensity. (h) Peak intensity loss observed on ${ }^{1} \mathrm{H},{ }^{15} \mathrm{~N}$ HSQC spectrum of Gal-1 bound to $\lambda 5$-UR after addition of SdiLN is reported on Gal-1 surface structure. (i) Schematic illustrating the Gal-1 selectivity change 
upon $\lambda 5$-UR interaction. Without $\lambda 5$-UR, Gal-1 acts as an exo-type lectin, binding to the terminal galactose. Upon $\lambda 5$-UR binding, Gal-1 is able to interact with the internal galactose and thus Gal-1 is converted into an endo-type lectin.

Figure 6. Model of Pre-BCR signaling regulation mediated by sialylated receptors recruitment as compared to BCR signaling. (a) CD22 dependent regulation of the B-cell receptor (BCR) signal (reviewed $\mathrm{in}^{66}$ ). CD22 forms oligomers by binding to sialylated receptors distinct from the $\mathrm{BCR}^{28}$. Upon specific antigen binding, conformational opening of the BCR occurs, followed by BCR activation and signaling through phosphorylation of Ig $\alpha / \beta$ complex. After activation, CD22 receptors are recruited to the BCR by cytoplasmic effectors and mediate BCR signaling inhibition. (b) Model for pre-BCR signaling regulation. In the absence of Gal-1, "CD22-like” receptors recognizing $\alpha 2,3$ sialylated ligands are clustered and can trigger signaling pathways involved in cell death. When Gal-1 interacts with the pre-BCR, specific targeting of $\alpha 2,3$ sialylated $\beta$-galactoside ligands occurs leading to receptors recruitment. The formation of a homogeneous protein platform favors efficient pre-BCR signaling leading to cell survival. In addition, this receptor segregation will create mechanical stress provoking membrane curvature and subsequent pre-BCR internalization. 
bioRxiv preprint doi: https://doi.org/10.1101/2022 02.08 .479506 : this version posted February 8,2022 . The copyriaht holder for this preprint (which was not certified by peer review) is the author/funder, who has granted bioRxiv a license to display the preprint in perpetuity. It is made available under aCC-BY 4.0 International license.

a

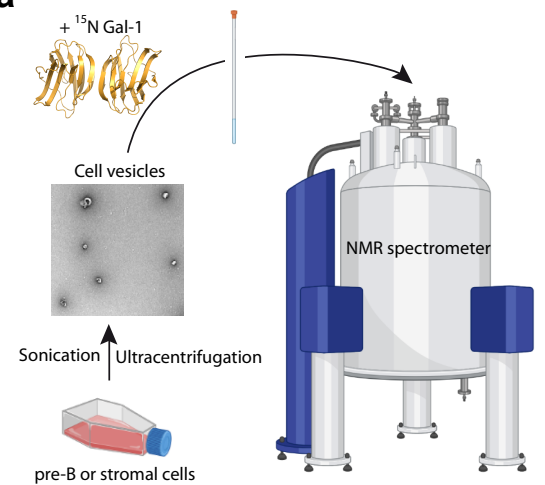

\section{Figure 1}

b

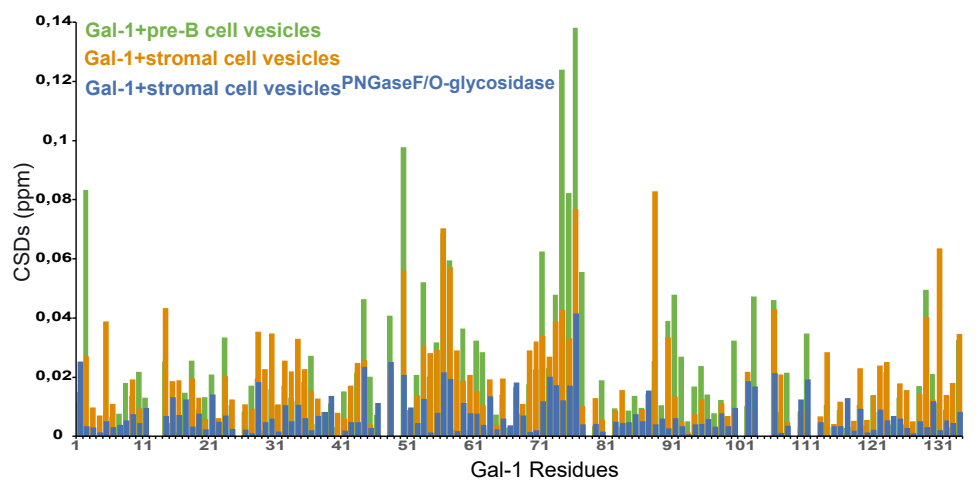

C

Gal-1+pre-B cell vesicles

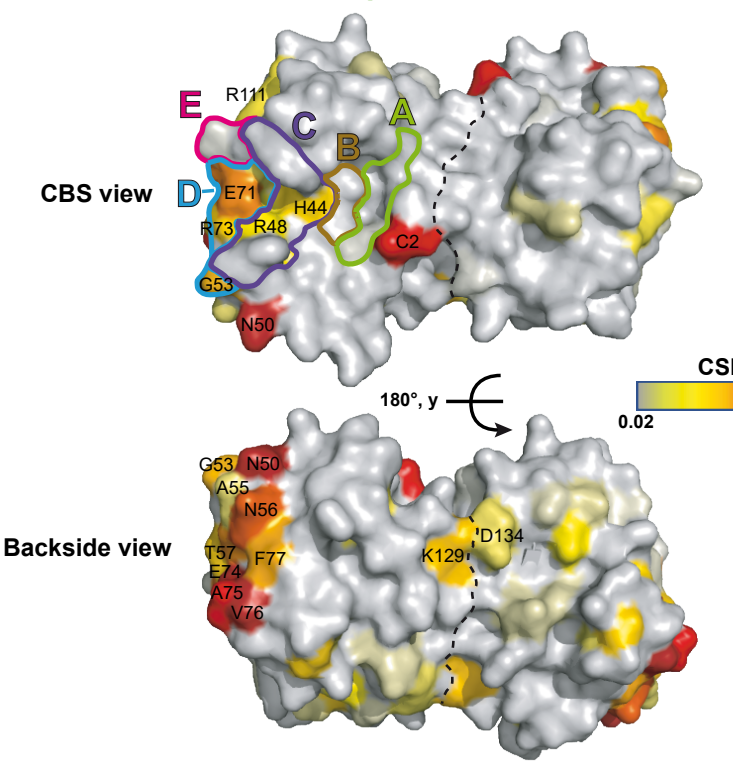

d Gal-1+stromal cell vesicles

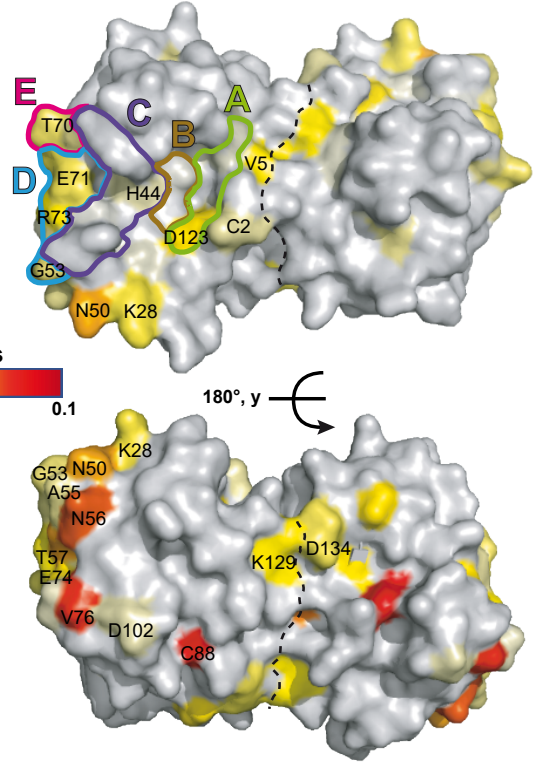


bioRxiv preprint doi: https://doi.org/10.1101/2022.02.08 479506 - this version posted February 8, 2022. The copyright holder for this preprint (which was not certified by peer review) is the author/funder, who has granted bioRxiv a license to display the preprint in perpetuity. It is made available under aCC-BY 4.0 International license.

\section{Figure 2}

a Gal1+ pre-B cell vesicles $+\lambda 5-U R$ Gal1+ pre-B cell vesicles $+\lambda 5$-UR-L26A-W30A

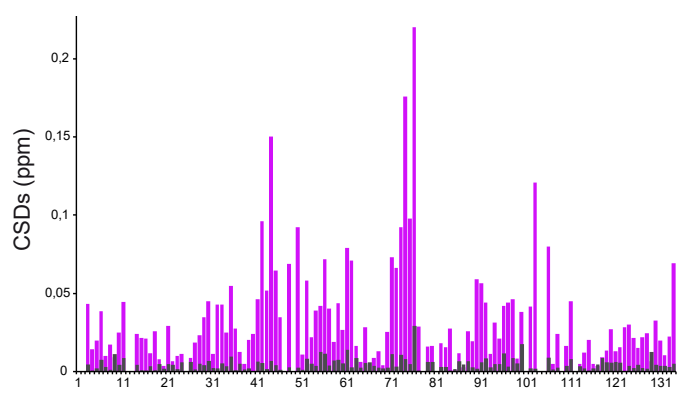

b Gal-1+pre-B cell vesicles $+\lambda 5-$ UR $\mathbf{d}$ Gal-1+mixed cell vesicles $+\lambda 5-\mathrm{UR}$

Gal-1 Residues

C Gal-1
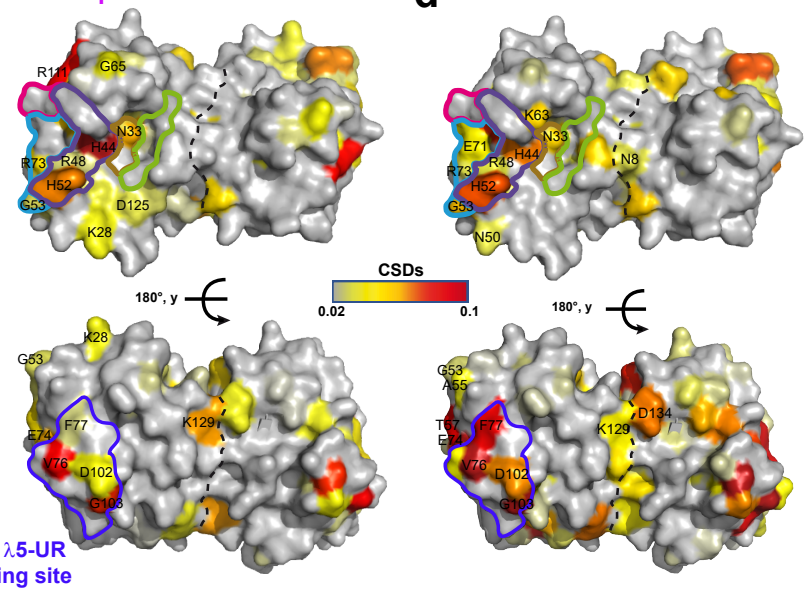

Gal-1+pre-B cell vesicles

Gal-1+pre-B cell vesicles $+\lambda 5-$ UR
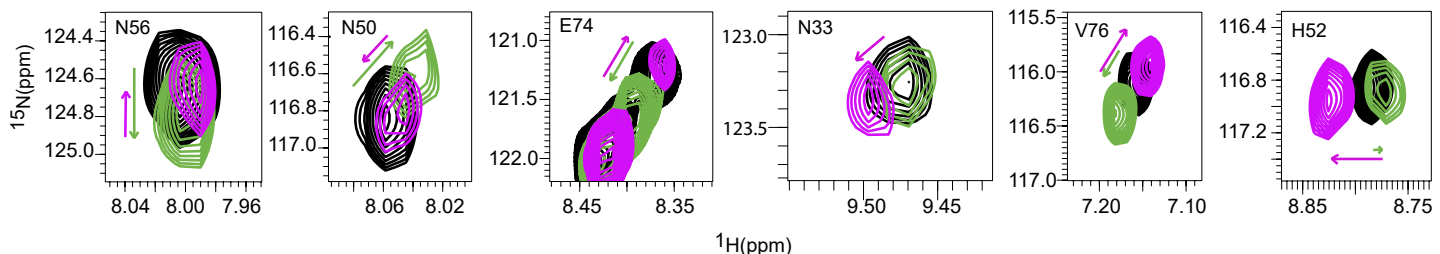
bioRxiv preprint doi: https://doi.org/10.1101/2022 02 08.479506. this version posted February 8.2022 . The copyriaht holder for this preprint (which was not certified by peer review) is the author/funder, who has granted bioRxiv a license to display the preprint in perpetuity. It is made available under aCC-BY 4.0 International license.

Figure 3

a

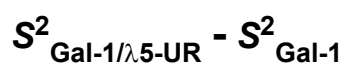

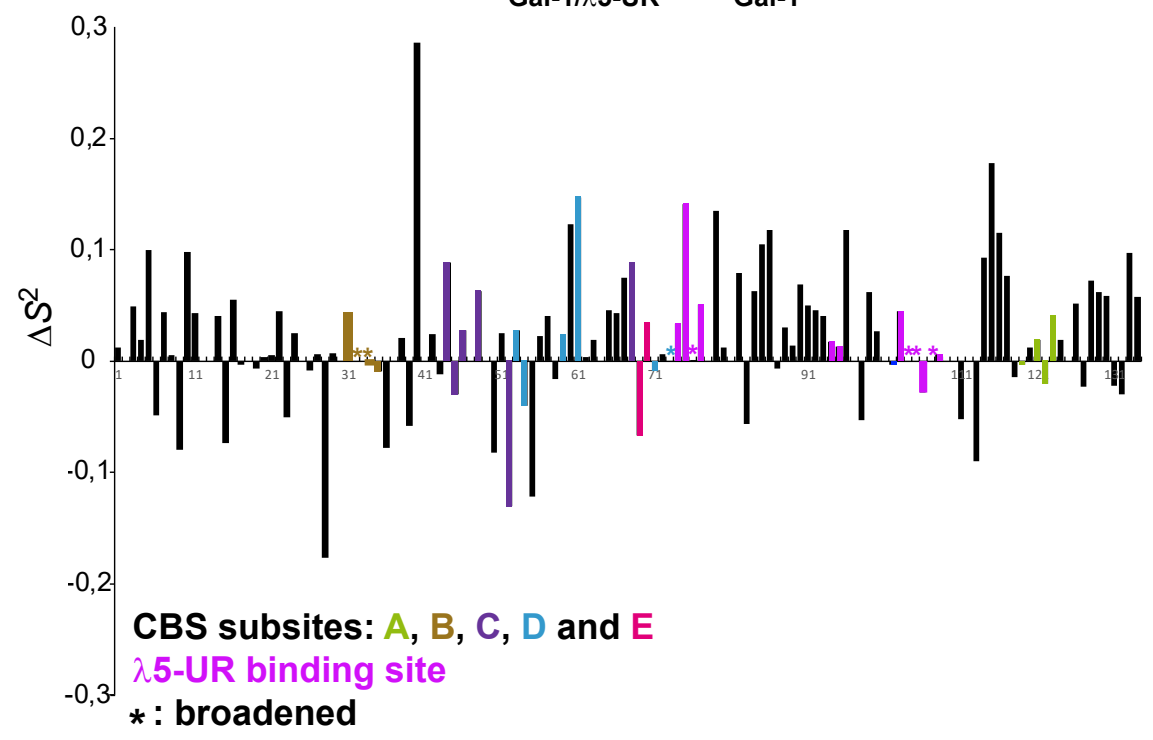

b

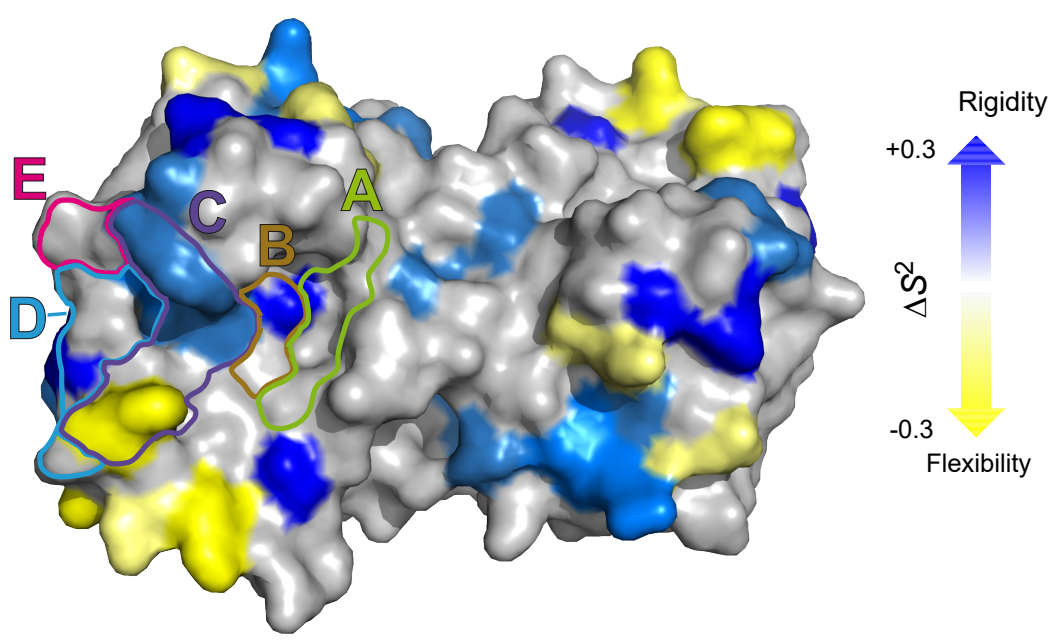


bioRxiv preprint doi: https://doi org/10.1101/2022.02 08.479506; this version posted February 8, 2022. The copyright holder for this preprint (which was not certified by peer review) is the author/funder, who has granted bioRxiv a license to display the preprint in perpetuity. It is made available under aCC-BY 4.0 International license.

Figure 4

a

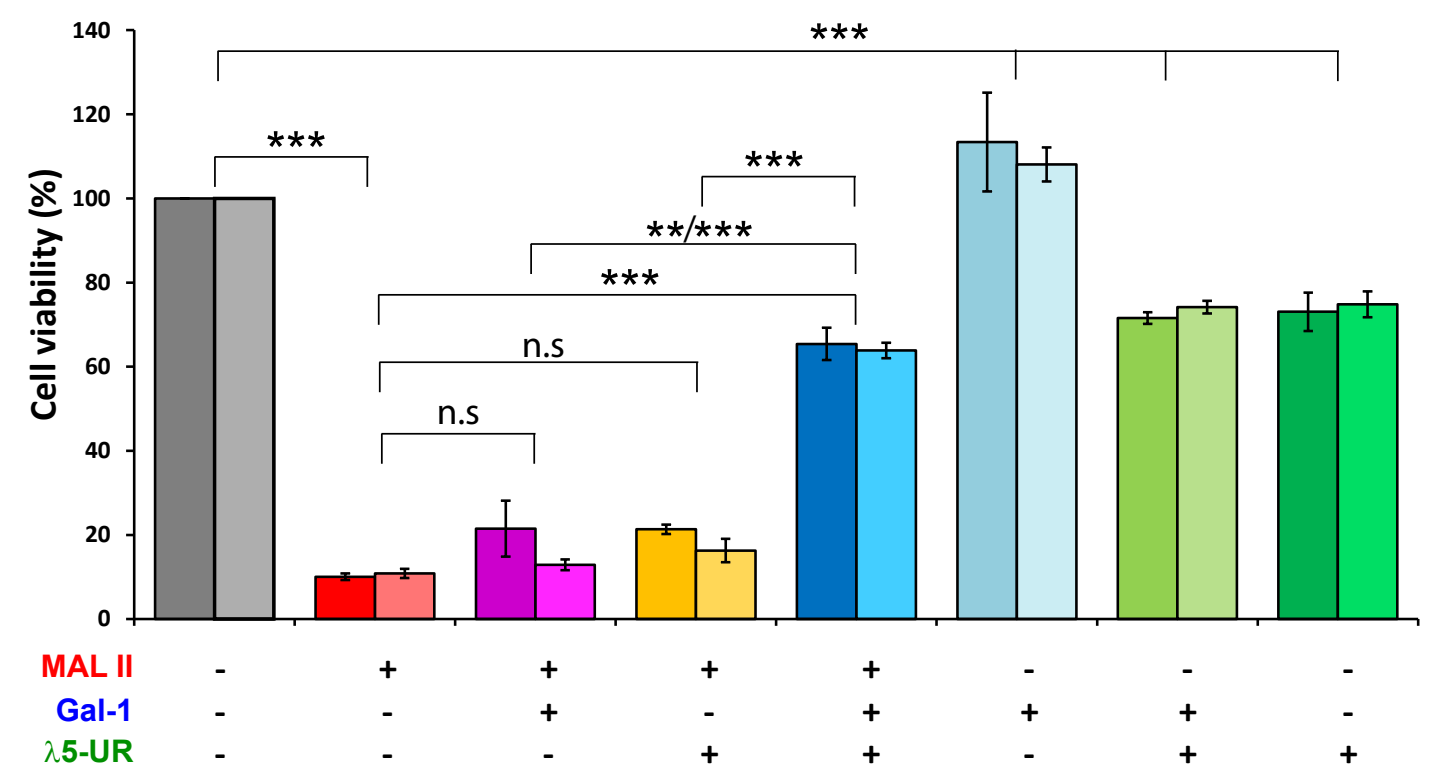

b

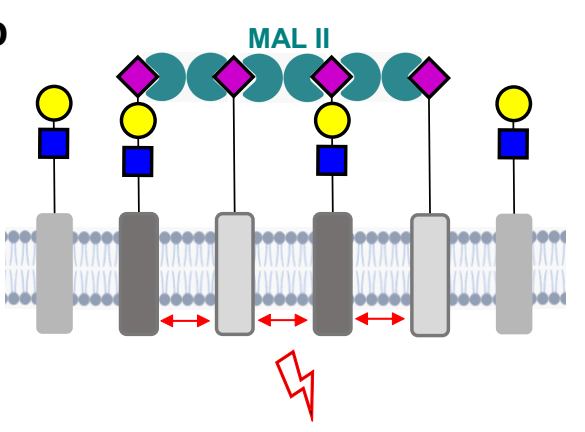

Cell death
C

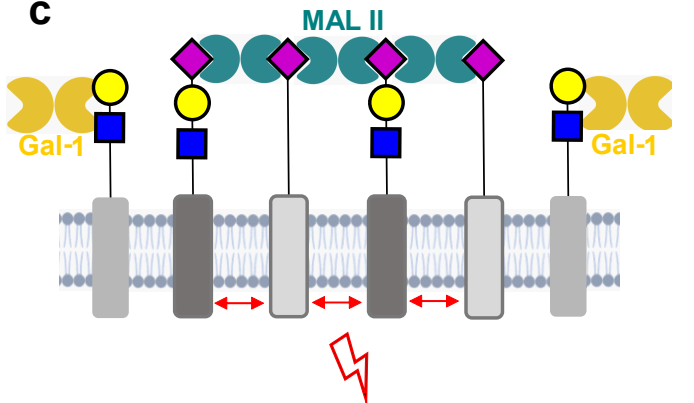

Cell death

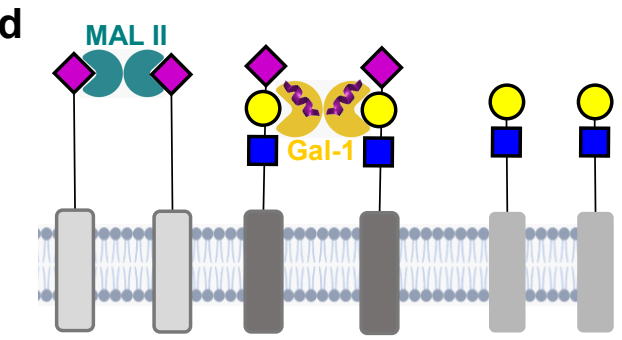

Cell survival

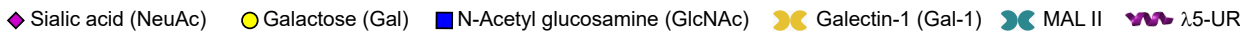


bioRxiv preprint doi: https//doi.org/10.1101/2022.02 08.479506 - this version posted February 8,2022 . The copyright holder for this preprint (which was not certified by peer review) is the author/funder, who has granted bioRxiv a license to display the preprint in perpetuity. It is made available under aCC-BY 4.0 International license.

a

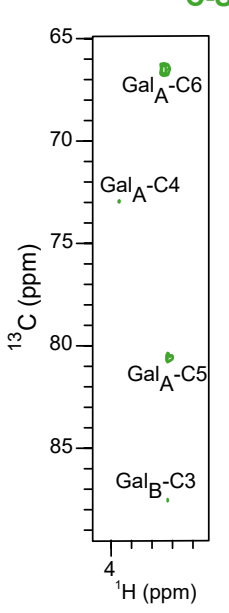

C

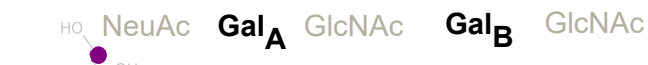

d

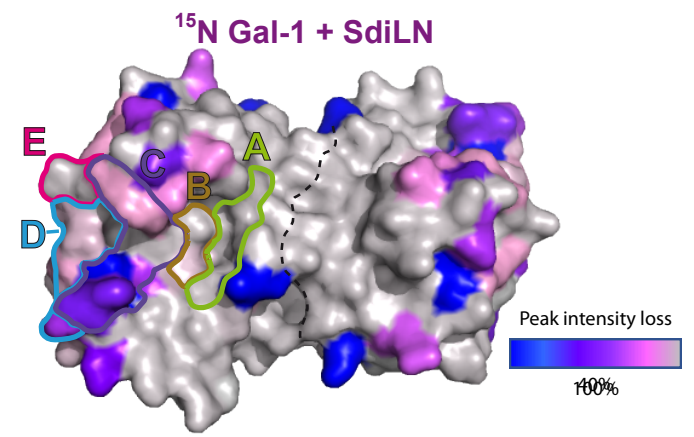

e

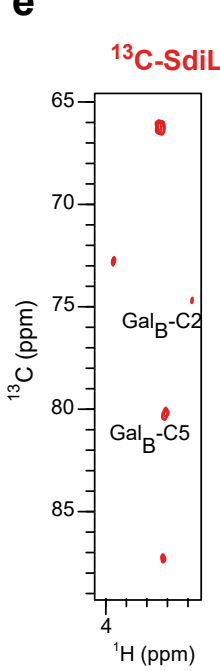

b ${ }^{13} \mathrm{C}-\mathrm{SdiLN}$

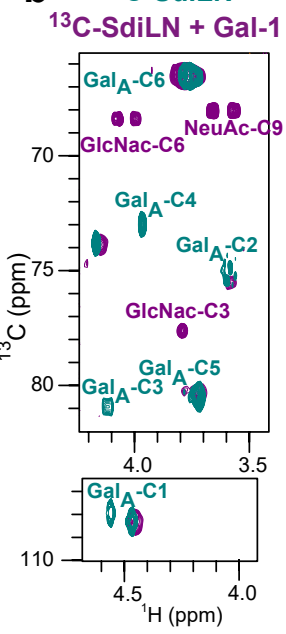

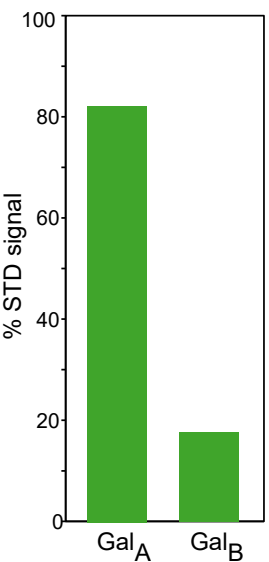

f

f ${ }^{13} \mathrm{C}$-SdiLN + Gal1 ${ }^{13} \mathrm{C}-\mathrm{SdiLN}+\mathrm{Gal}-1+\lambda 5$-UR

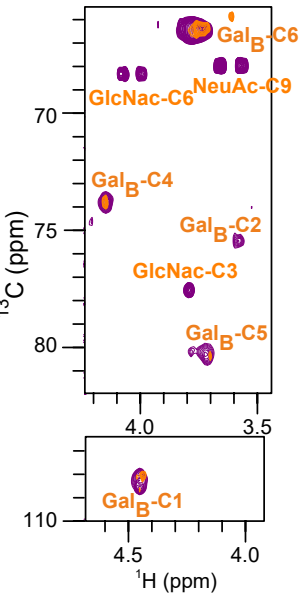

g
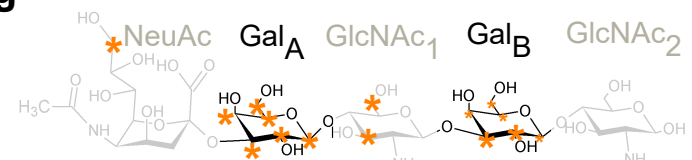

h $\quad{ }^{15} \mathrm{~N} \mathrm{Gall}-1+$ SdiLN + $\lambda 5$-UR

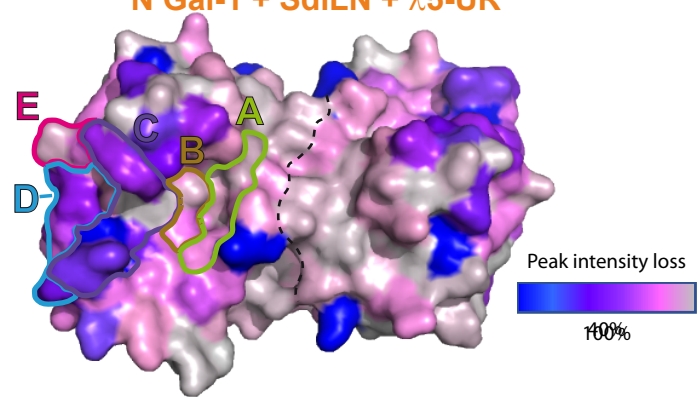

i

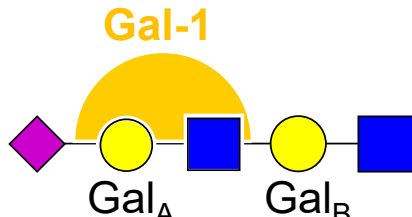

Exo-type lectin $\lambda$ 5-UR

binding

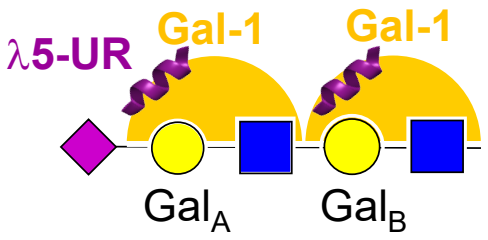

Endo-type lectin 
Figure 6

a

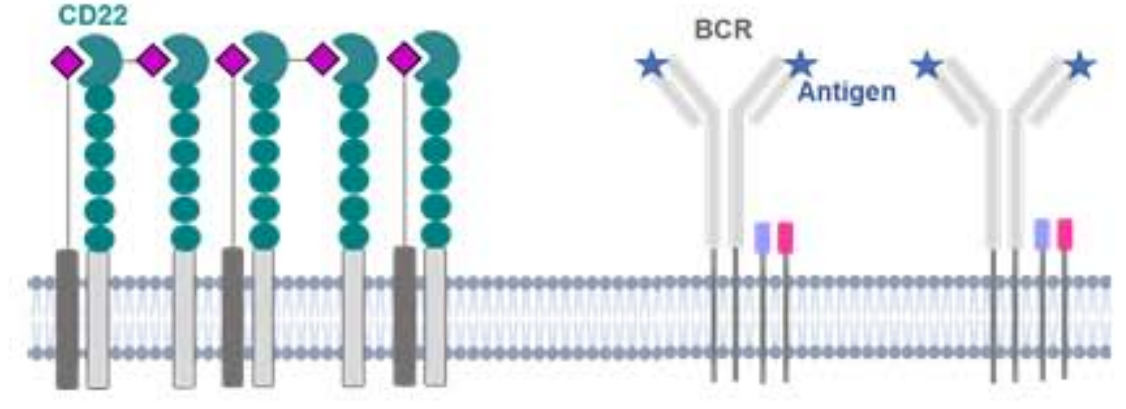

CD22

recuitment

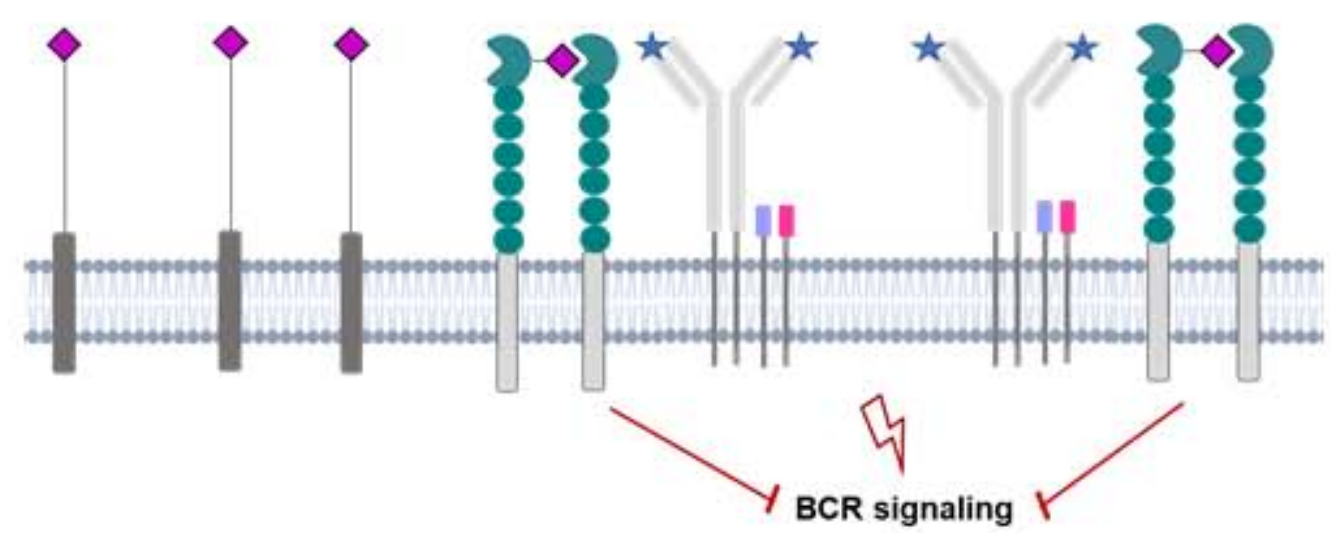

b

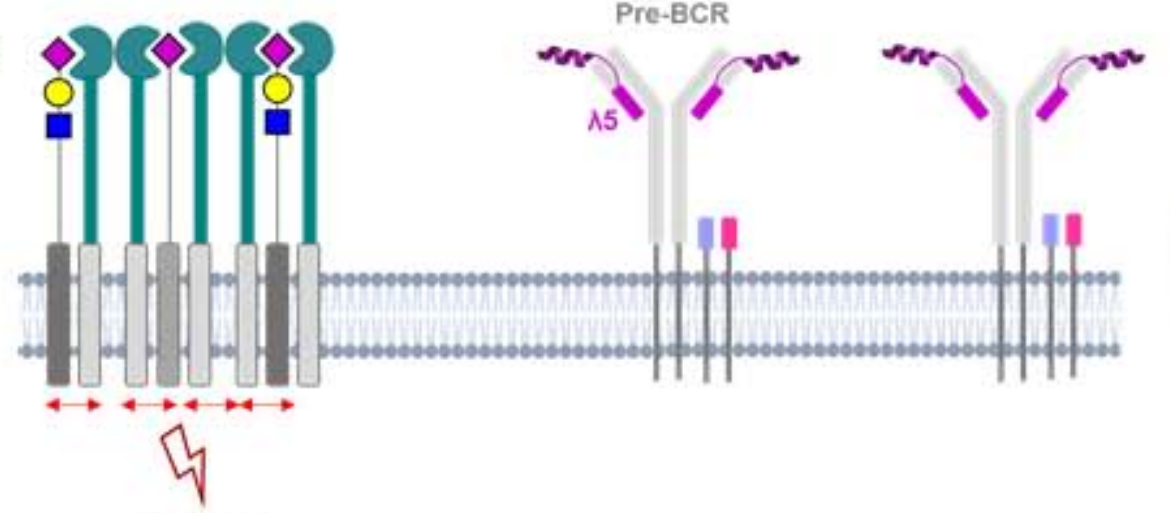

Cell death
Gal-1 mediated recuitment

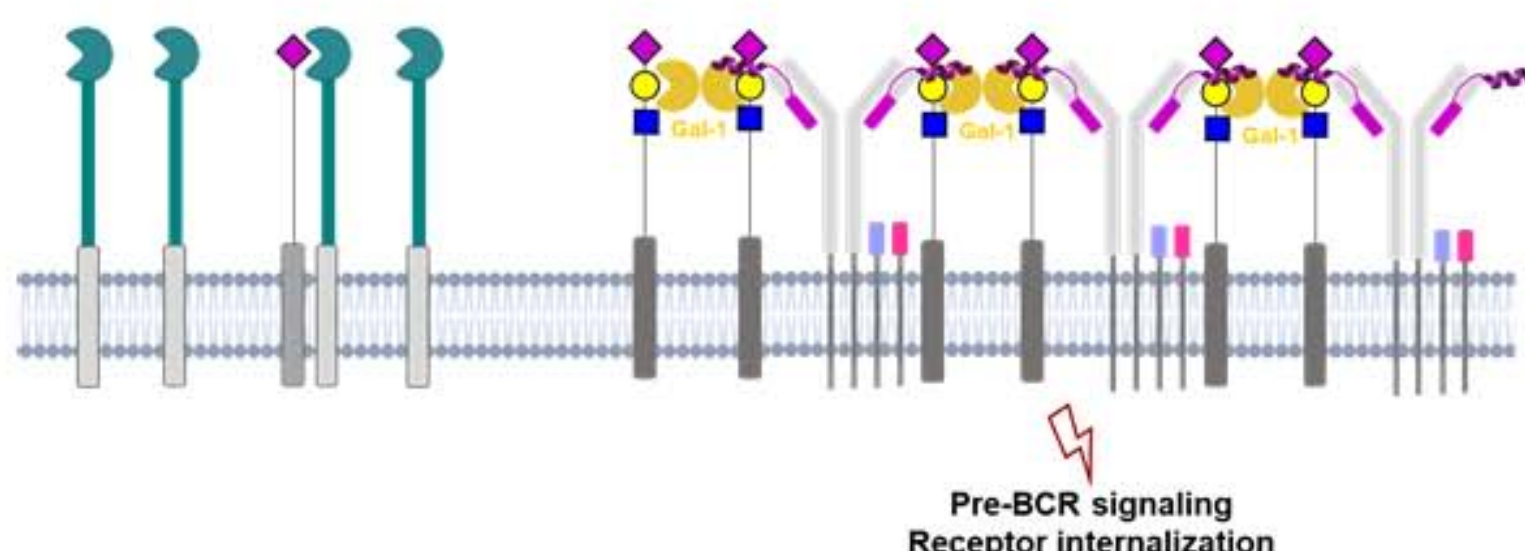

Receptor internalization Cell survival

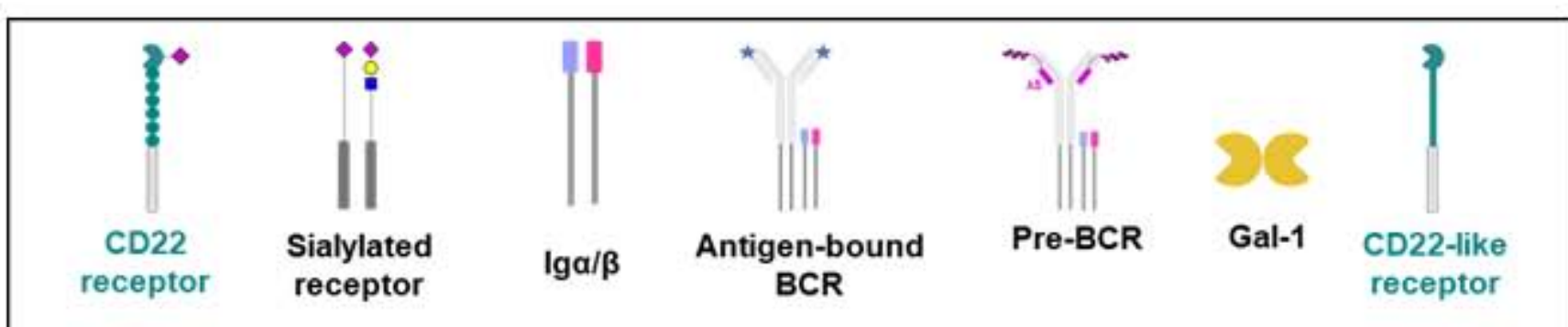

